\title{
Primary Studies on Construction and Evaluation of Ion-Sensitive in situ Gel Loaded with Paeonol-Solid Lipid Nanoparticles for Intranasal Drug Delivery
}

This article was published in the following Dove Press journal: International Journal of Nanomedicine

Yue Sun'
Lingjun Li'
Huichao Xie'
Yuzhen Wang'
Shuang Gao'
Li Zhang'
Fumin Bo'
Shanjing Yang'
Anjie Feng'
'College of Pharmacy, Shandong
University of Traditional Chinese
Medicine, Jinan 250355, People's Republic
of China; ${ }^{2}$ School of Pharmacy, Shenyang
Pharmaceutical University, Shenyang
I I00I6, People's Republic of China

Correspondence: Lingjun Li Email sdzyylilingjun@163.com
Background: Paeonol (PAE) is a potential central neuroprotective agent with poor water solubility and rapid metabolism in vivo. The key to improve the clinical application of PAE in the treatment of neurodegenerative diseases is to improve the brain delivery of it. The purpose of this study was to construct a paeonol-solid lipid nanoparticles-in situ gel (PAESLNs-ISG) drug delivery system based on nose-brain transport pathway.

Materials and Methods: In this study, the stability of PAE in simulated biological samples was studied firstly in order to clarify the reasons for low oral bioavailability. Paeonol-solid lipid nanoparticles (PAE-SLNs) were prepared by high-temperature emulsification-low-temperature curing combined with ultrasound. The PAE-SLNs-ISG drug delivery system was constructed, and related formulation optimization, preparation characterization, cell evaluation and in vivo evaluation were performed.

Results: The metabolic mechanism of PAE incubated in the liver microsomes metabolic system was in accordance with the first-order kinetics, and the half-life was $0.23 \mathrm{~h}$. PAESLNs were polyhedral or spherical particles with good dispersion and the particle size was $166.79 \mathrm{~nm} \pm 2.92 \mathrm{~nm}$. PAE-SLNs-ISG solution was a Newtonian fluid with a viscosity of $44.36 \mathrm{mPa} \cdot \mathrm{S} \pm 2.89 \mathrm{mPa} \cdot \mathrm{S}$. The viscosity of PAE-SLNs-ISG gel was $1542.19 \mathrm{mPa} \cdot \mathrm{S} \pm$ $19.30 \mathrm{mPa} \cdot \mathrm{S}$, and the rheological evaluation showed that the gel was a non-Newtonian pseudoplastic fluid with shear thinning, thixotropy and yield value. The release mechanism of PAE from PAE-SLNs was drug diffusion; the release mechanism of PAE from PAE-SLNsISG was a synergistic effect of skeleton erosion and drug diffusion. The cell viabilities of PAE-SLNs and PAE-SLNs-ISG in the concentration range of $0.001 \mu \mathrm{g} / \mathrm{mL}$ to $10 \mu \mathrm{g} / \mathrm{mL}$ were higher than $90 \%$, showing a low level of cytotoxicity. The geometric mean fluorescent intensities of RPMI 2650 cells incubated with fluorescein isothiocyanate-solid lipid nanoparticles (FITC-SLNs) for $1 \mathrm{~h}, 4 \mathrm{~h}$ and $6 \mathrm{~h}$ were $1841 \pm 24,2261 \pm 27$ and $2757 \pm 22$, respectively. Cyanine7 NHS ester-solid lipid nanoparticles-in situ gel (Cy7-SLNs-ISG) accumulated effectively in the brain area after administration through the olfactory area, and the fluorescence response was observed in olfactory bulb, cerebellum and striatum.

Conclusion: SLNs-ISG nose-brain drug delivery system can effectively deliver SLNs to brain regions, and it is a potentially effective strategy to realize the brain region delivery of PAE.

Keywords: paeonol, in vitro metabolism, solid lipid nanoparticles, in situ gel, nose-brain transport

\section{Introduction}

Paeonol (PAE, 2'-Hydroxy-4'-methoxyacetopheone) is a potential central neuroprotective agent that has potential therapeutic effects on many central neurodegenerative 
diseases, such as cerebral hypoglycemia hypoxiareperfusion injury, Alzheimer's disease, Parkinson's disease, depression, neuronal aging and neuroinflammation. ${ }^{1}$ PAE belongs to Biopharmaceutics Classification System (BCS) class II drugs. PAE is poorly water-soluble, which affects its passage through the hydration layer on the surface of the epithelial cells and thus affects gastrointestinal absorption. $^{2}$ The pharmacokinetic results of PAE administered by oral and intravenous injection showed that its metabolism in vivo was rapid and it was difficult to maintain effective plasma concentration. ${ }^{3}$ The blood-brain barrier (BBB) ensures the central nervous system to maintain a high degree of homeostasis by strictly controlling the exchange of endogenous and exogenous substances between the brain area and the outside world. Fat-soluble molecules less than 400 Da can pass through BBB more effectively. Paeonol can be actively transported from circulating blood through $\mathrm{BBB}$ to the brain region. Its transport mechanism involves a carrier-mediated transport system, and the transport efficiency is closely related to concentration, $\mathrm{pH}$ and energy. ${ }^{4}$ The key to improve the clinical application of PAE in the treatment of neurodegenerative diseases is to improve the brain delivery of it.

Solid lipid nanoparticles technology is a nanoformulation based on the combination of solid lipid and liquid lipid as carrier material, which has obvious advantages in enhancing the stability of drugs in vivo and ensuring the biocompatibility of drug carriers. ${ }^{5}$ It is considered to be one of the most promising nano-drug delivery systems to be developed and put on the market. Solid lipid nanoparticles have a good effect on the loading of fat-soluble drugs. Drugs are encapsulated in the core in molecular or amorphous form and can be released slowly. ${ }^{6}$

As a brain-targeting strategy, nose-brain transport pathway has been paid more and more attention by researchers, which can avoid the hepatic first-pass effect, bypass the blood-brain barrier, achieve non-invasive drug delivery and improve the bioavailability of brain regions. ${ }^{7}$ The main pathways of nose-brain transport are nerve pathway, mucous pathway, blood circulation pathway and lymphoid pathway. ${ }^{8,9}$ The neural pathway mainly based on olfactory nerve transmission is also called direct pathway, which can transport drugs directly from the olfactory area to the brain region with high transmission efficiency. ${ }^{10}$

The secretion of nasal mucus, the nasal clearance caused by the rapid swinging of nasal cilia and the permeability of nasal mucosa are the main limitations of nasal administration. ${ }^{11}$ In situ gel is a new type of environmental response hydrogel, which can be used not only as drug storage but also as drug delivery carrier. ${ }^{12}$ The solution state of the gel before phase transition was a Newtonian fluid, which maintained a stable low viscosity level, made the preparation have good flowability, and was convenient for drug administration and dose control. After phase transformation, the gel was a typical pseudo-plastic nonNewtonian fluid with high viscosity and strength, as well as the rheological characteristics of shear thinning and thixotropic stress. In situ gel can be used in ophthalmic administration, nasal administration, rectal administration, vaginal administration and blood injection. ${ }^{13}$ According to the different response conditions, in situ gel can be divided into thermosensitive in situ gel, ion-sensitive in situ gel, $\mathrm{pH}-$ sensitive in situ gel and photosensitive in situ gel. ${ }^{13-16}$

In this study, the stability of PAE in simulated biological samples was studied firstly in order to clarify the reasons for low oral bioavailability. PAE had the pharmacokinetic characteristics of liver first-pass effect and rapid blood metabolism, which required a new delivery strategy to achieve its effective brain area accumulation. The purpose of this study was to construct a paeonol-solid lipid nanoparticles-in situ gel (PAE-SLNs-ISG) drug delivery system based on nose-brain transport pathway, and to perform related formulation optimization, preparation characterization, cell evaluation and in vivo evaluation.

\section{Materials and Methods Materials}

Paeonol (PAE > 99\%) was purchased from National Institutes for Food and Drug Control (Beijing, China). Dialysis bag $(\mathrm{MW}=3500 \mathrm{Da})$ and Centrifugal filters (4 mL, MW = $3000 \mathrm{Da}$ ) were obtained from Amicon (Darmstadt, Germany). Fluorescein isothiocyanate (FITC), Cyanine7 NHS ester (Cy7), Deacetylated gellan gum (DGG), Vitamin E (VE), (4,5-Dimethylthiazol-2-yl) -2,5-diphenyltetrazo-liumbrom-ide (MTT) and 4',6-diamidino-2-phenylindole (DAPI) were purchased from Sigma-Aldrich (St. Louis, MO, USA). Female SD rat liver microsomes and NADPH incubation system were purchased from the research Institute for Liver Diseases Co. Ltd. (Shanghai, China). Pepsin, trypsin, glycerin monostearate, soybean lecithin, poloxamer, Tween-80, mannitol, chlorinated acetate, glycerin (VG), borate buffer ( $\mathrm{pH}$ 7.4) were obtained from Shanghai Yuanye Biological Technology Co., Ltd. (Shanghai, China). RPMI 2650 cells were purchased from the Cell Bank of the Chinese Academy of Sciences (Shanghai, China). Male nude 
mice $(20 \pm 2 \mathrm{~g})$ and Sprague-Dawley rats $(200 \pm 20 \mathrm{~g})$ were purchased from Wuhan Sericebio Co., Ltd. (Wuhan, China). Animal experiments were performed with the approval of the Laboratory Animal Ethics Committee at Shandong University of Traditional Chinese Medicine and followed the guidelines of the National Act on the Use of Experimental Animals (China).

\section{Stability of PAE in Simulated Biological Samples \\ Method for Content Determination of PAE}

The content of PAE was determined by High Purity Liquid Chromatography (HPLC). The Agilent 1260 equipped with a UV detector and a Kromasil 100-5-C18 column (4.6 × $250 \mathrm{~mm}, 5 \mu \mathrm{m})$. The column temperature was $30^{\circ} \mathrm{C}$, the mobile phase was methanol (60\%): deionized water $(40 \%)$, and the wavelength was $274 \mathrm{~nm}$. The standard curve for the concentration $(\mathrm{X})$ and peak area $(\mathrm{Y})$ of paeonol was $\mathrm{Y}=97.569 \mathrm{X}+11.766, \mathrm{R}^{2}=0.9999$.

\section{Artificial Gastric Juice}

According to the requirements of the 2015 edition of Chinese Pharmacopoeia, artificial gastric juice was prepared: $16.40 \mathrm{~mL}$ of dilute hydrochloric acid, $800 \mathrm{~mL}$ of deionized water and $10 \mathrm{~g}$ of pepsin were mixed, and the volume was fixed to $1000 \mathrm{~mL}$ with deionized water. $52.40 \mathrm{mg}$ of paeonol standard was accurately weighed and dissolved in methanol to a concentration of $10.48 \mathrm{mg} / \mathrm{mL}$ as the stock solution. One hundred microliters of paeonol stock solution was added to $10 \mathrm{~mL}$ of artificial gastric juice and incubated at $75 \mathrm{rpm}$. No pepsin was used as a negative control group. $0.5 \mathrm{~mL}$ was sampled at $0.25 \mathrm{~h}, 0.5 \mathrm{~h}, 1 \mathrm{~h}, 1.5 \mathrm{~h}, 2 \mathrm{~h}, 3 \mathrm{~h}, 4 \mathrm{~h}$ and $6 \mathrm{~h}$, respectively. Each time point was an independent group. The sample was immediately added to $1 \mathrm{~mL}$ of methanol $\left(4^{\circ} \mathrm{C}\right)$, oscillated by vortex for $1 \mathrm{~min}$, and centrifuged at $12,000 \mathrm{rpm}$ for $15 \mathrm{~min}$. The supernatant was taken, passed through a $0.22 \mu \mathrm{m}$ microporous membrane, and the content of paeonol was determined by HPLC. Each group was operated in parallel for three times. The experiment was carried out at $37^{\circ} \mathrm{C}$.

\section{Artificial Intestinal Juice}

Artificial intestinal juice was prepared according to the 2015 edition of Chinese Pharmacopoeia: $6.80 \mathrm{~g}$ of potassium dihydrogen phosphate was accurately weighed and dissolved in $500 \mathrm{~mL}$ of deionized water. The $\mathrm{pH}$ value was adjusted to 6.8 with $\mathrm{NaOH}$ solution $(0.1 \mathrm{~mol} / \mathrm{L})$. Ten grams of trypsin was taken and dissolved in deionized water. The two liquids were mixed and diluted to $1000 \mathrm{~mL}$ with deionized water. One hundred microliters of paeonol stock solution $(10.48 \mathrm{mg} / \mathrm{mL})$ was added to $10 \mathrm{~mL}$ of artificial intestinal juice and incubated at $75 \mathrm{rpm}$. No trypsin was used as a negative control group. $0.5 \mathrm{~mL}$ was sampled at $0.25 \mathrm{~h}, 0.5 \mathrm{~h}, 1 \mathrm{~h}, 1.5 \mathrm{~h}, 2 \mathrm{~h}, 3 \mathrm{~h}, 4 \mathrm{~h}$ and $6 \mathrm{~h}$, respectively. Each time point was an independent group. The sample was immediately added to $1 \mathrm{~mL}$ of methanol $\left(4^{\circ} \mathrm{C}\right)$, oscillated by vortex for $1 \mathrm{~min}$, and centrifuged at 12,000 rpm for $15 \mathrm{~min}$. The supernatant was taken, passed through a $0.22 \mu \mathrm{m}$ microporous membrane, and the content of paeonol was determined by HPLC. Each group was operated in parallel for three times. The experiment was carried out at $37^{\circ} \mathrm{C}$.

\section{Liver Microsomes}

A quantity of $16.60 \mathrm{mg}$ of paeonol standard was precisely weighed and dissolved in methanol to $1.66 \mathrm{mg} / \mathrm{mL}$. A quantity of $880 \mu \mathrm{L}$ of phosphate buffer $(0.1 \mathrm{M}, \mathrm{pH} 7.4)$ was mixed with $50 \mu \mathrm{L}$ of liver microsomes $(20 \mathrm{mg} / \mathrm{mL})$ and incubated at $37^{\circ} \mathrm{C}$ for $5 \mathrm{~min}$. The NADPH incubation system (containing $50 \mu \mathrm{L}$ of solution $\mathrm{A}$ and $10 \mu \mathrm{L}$ of solution $\mathrm{B}$, mixed in an ice bath at $0^{\circ} \mathrm{C}$ ) and $10 \mu \mathrm{L}$ of paeonol solution $(1.66 \mathrm{mg} / \mathrm{mL})$ were added and the incubation was continued in a water bath at $37^{\circ} \mathrm{C}$. The total volume of the incubation system was $1 \mathrm{~mL}$. The incubation system without NADPH was the negative control group. The reaction was terminated by adding $2 \mathrm{~mL}$ of ice methanol solution at $5 \mathrm{~min}, 10 \mathrm{~min}, 20 \mathrm{~min}$ and $30 \mathrm{~min}$, respectively. Each time point was an independent group. Samples were oscillated by vortex for $1 \mathrm{~min}$ and centrifuged at 12,000 rpm for $15 \mathrm{~min}$. The supernatant was taken, passed through a $0.22 \mu \mathrm{m}$ microporous membrane, and the content of paeonol was determined by HPLC. Each set of experiments was run in parallel for three times.

\section{Preparation and Characterization of PAE-SLNs Preparation of PAE-SLNs}

PAE-SLNs were prepared by high-temperature emulsification-low-temperature curing combined with ultrasound (Figure 1A). Glycerin monostearate $(100 \mathrm{mg})$, soybean lecithin $(200 \mathrm{mg})$ and paeonol $(10 \mathrm{mg})$ were dissolved in acetone: anhydrous ethanol $\left(1: 1,5 \mathrm{~mL}\right.$, and $\left.75^{\circ} \mathrm{C}\right)$ as organic phase. Poloxamer (125 mg) and Tween-80 $(125 \mathrm{mg})$ were dissolved in deionized water $\left(15 \mathrm{~mL}, 75^{\circ}\right.$ C) as water phase. The organic phase was blended 


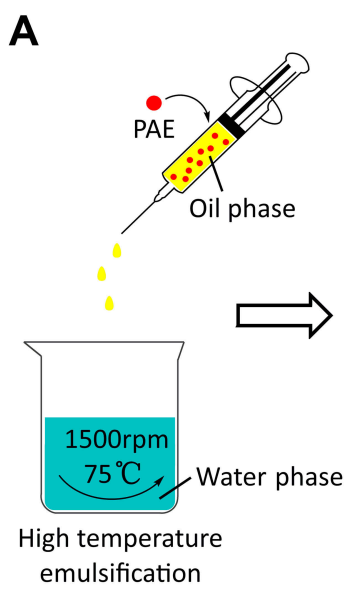

B

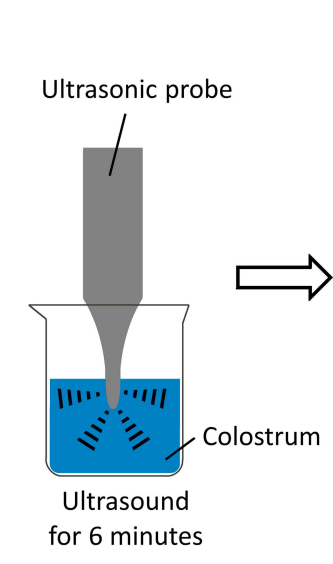

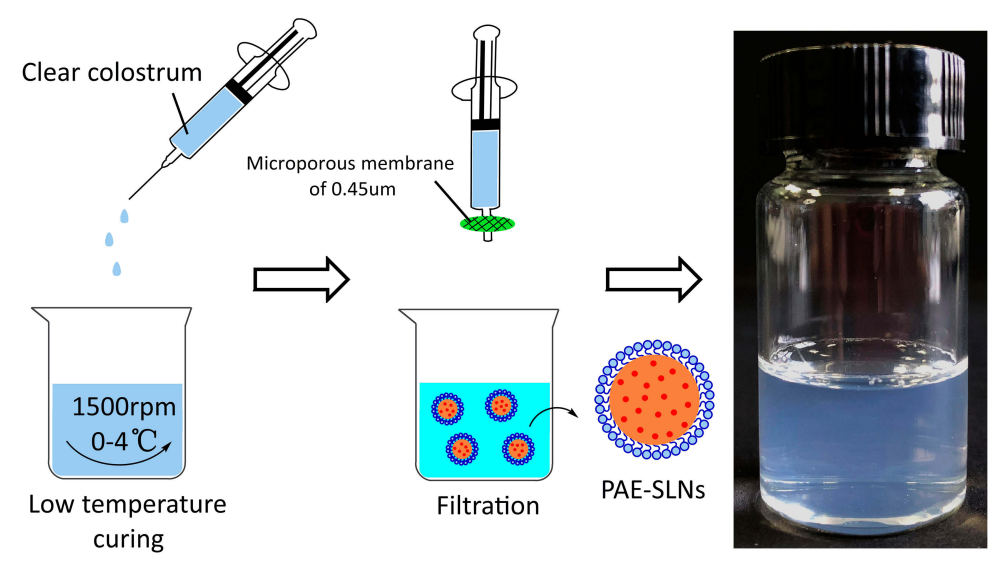
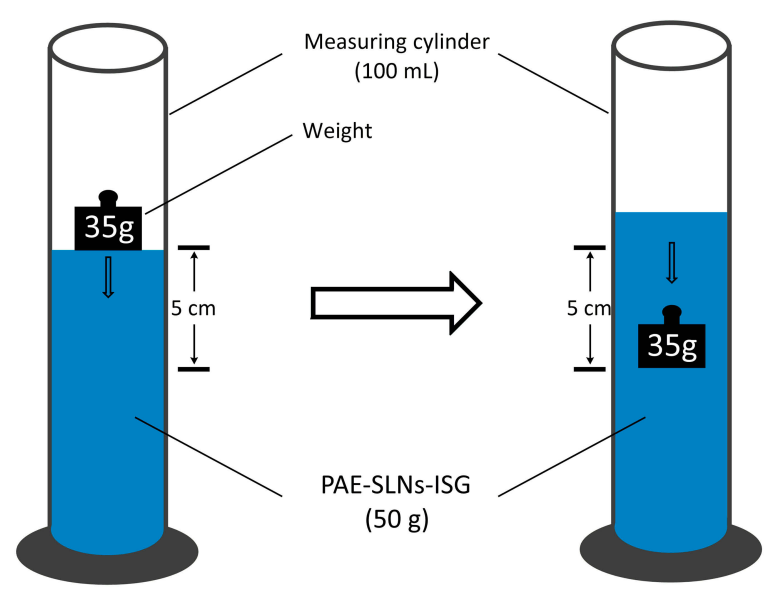

\section{C}

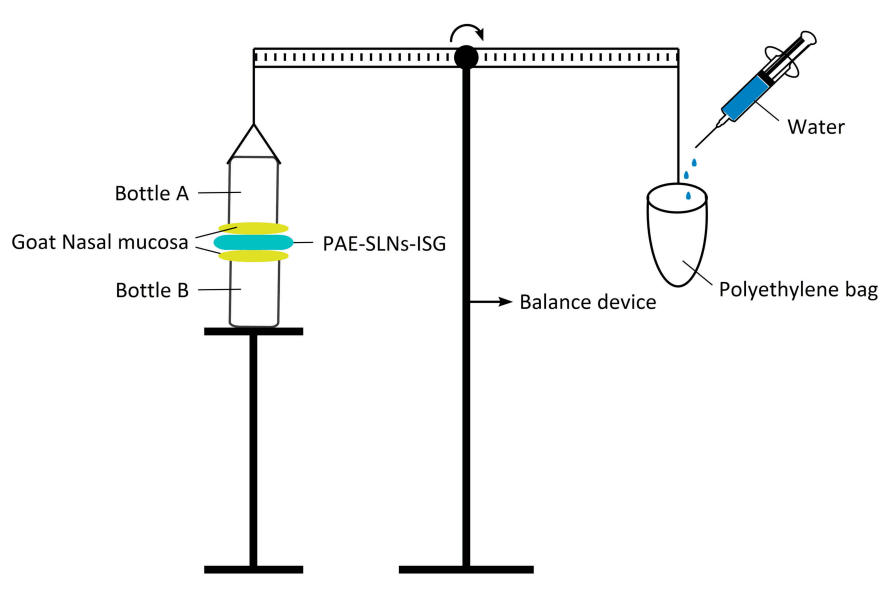

Figure I (A) The scheme of preparation of PAE-SLNs by high-temperature emulsification-low-temperature curing combined with ultrasound. (B) Test scheme for gel strength. (C) Determination of in vitro mucoadhesion strength of gel by improved physical equilibrium method.

Abbreviations: PAE, paeonol; PAE-SLNs, paeonol-solid lipid nanoparticles; PAE-SLNs-ISG, paeonol-solid lipid nanoparticles-in situ gel.

dropwise to the water phase under intense magnetic stirring. The stirring continued for $1.5 \mathrm{~h}$ at $1500 \mathrm{rpm}$ and the emulsification temperature was maintained at $75^{\circ} \mathrm{C}$. PAE was stable at $75^{\circ} \mathrm{C}$. The reaction was stopped until the organic solvent was completely evaporated and the colostrum system was concentrated to $10 \mathrm{~mL}$. The colostrum was sonicated with an ultrasound probe for 6 min (working for $3 \mathrm{~s}$, interval for $3 \mathrm{~s}$ ). The colostrum was quickly injected into deionized water $\left(2^{\circ} \mathrm{C}, 20 \mathrm{~mL}\right)$ under intense stirring. Stirring was continued for $2 \mathrm{~h}$ at $1500 \mathrm{rpm}$, the temperature of solidification in an ice bath was kept between $0^{\circ} \mathrm{C}$ and $4{ }^{\circ} \mathrm{C}$. The clear solution with blue light was the PAE-SLNs colloidal solution. The PAE-SLNs colloidal solution was added to a dialysis bag ( $\mathrm{MW}=$ $3500 \mathrm{Da})$ and dialyzed in distilled water $\left(2^{\circ} \mathrm{C}\right)$ for $3 \mathrm{~h}$ to remove excess surfactants. The colloidal solution was passed through a $0.45 \mu \mathrm{m}$ microporous membrane. After pre-freezing at $-80^{\circ} \mathrm{C}$, it was freeze-dried to obtain PAESLNs freeze-dried powder.

The preparation of blank solid lipid nanoparticles (bSLNs) was the same as that of PAE-SLNs, except that no PAE was added. FITC-SLNs and Cy7-SLNs were prepared by the same process by replacing PAE $(10 \mathrm{mg})$ with FITC $(10 \mathrm{mg})$ or Cy7 $(10 \mathrm{mg})$.

\section{Characterization of PAE-SLNs}

\section{Encapsulation Efficiency}

The drug encapsulation efficiency (EE\%) was determined by ultrafiltration centrifugation. Three milliliters of PAESLNs colloidal solution was placed in a $4 \mathrm{~mL}$ ultrafiltration centrifuge tube $(\mathrm{MW}=3500 \mathrm{Da})$ and centrifuged at $3000 \mathrm{rpm}$ for $40 \mathrm{~min}$. The liquid in the lower part of the tube was collected and the content of free PAE was determined by HPLC. The liquid in the upper part of the tube was placed in a volumetric flask and the volume was fixed 
to $10 \mathrm{~mL}$ with methanol. The sample was demulsified by ultrasound for $5 \mathrm{~min}$ and centrifuged at $12,000 \mathrm{rpm} / \mathrm{min}$ for $15 \mathrm{~min}$. The supernatant was taken and the content of PAE loaded was determined by HPLC. The EE\% of PAE loaded in PAE-SLNs was calculated by the formula:

$$
E E \%=\frac{\text { Amount of PAE in PAE }- \text { SLNs }}{\text { Total amount of PAE added }} * 100 \%
$$

\section{Particle Size and Zeta Potential}

Appropriate amounts of bSLNs, PAE-SLNs, FITC-SLNs and Cy7-SLNs freeze-dried products were weighed and dissolved into $0.1 \mathrm{mg} / \mathrm{mL}$ with deionized water, respectively. The particle size and zeta potential of SLNs were determined using a dynamic light scattering (DLS) particle size analyzer (Zetasizer Nano ZS, Malvern Instruments Ltd, UK). Experiments were carried out three times.

\section{Transmission Electron Microscopy (TEM)}

The surface topography of PAE-SLNs was observed by TEM. PAE-SLNs were dissolved in deionized water to $0.1 \mathrm{mg} / \mathrm{mL}$, dispersed by ultrasound for $3 \mathrm{~min}$, and negatively stained with $2 \%$ phosphotungstic acid solution for $3 \mathrm{~min}$. One drop was dripped on the ultra-thin carbon film, dried naturally and observed under the condition of $200 \mathrm{kV}$.

\section{Fourier Transform Infrared Spectrum (FTIR)}

PAE monomer, physical mixture, bSLNs and PAE-SLNs were ground and pressed with fully dried $\mathrm{KBr}$ particles under infrared lamp to prepare test samples, respectively. FTIR spectra were obtained from the Fourier infrared spectrometer (Agilent 660-IR, California, USA), and the wavenumber ranged from 4000 to $400 \mathrm{~cm}^{-1}$.

\section{X-Ray Diffraction Analysis (XRD)}

The crystal structures of PAE monomer, physical mixture, bSLNs and PAE-SLNs were characterized by an X-ray powder diffractometer. The uniform samples of $100 \mathrm{mg}$ were weighed, respectively, at room temperature, $\mathrm{Cu}-\mathrm{Ka}$ target, monochromator diffraction beam of graphite monochromator, tube flow: $40 \mathrm{~mA}$, high pressure: $40 \mathrm{kV}$, scanning speed: $5^{\circ} \cdot \min ^{-1}$, sweep angle $(\theta): 0 \sim 90^{\circ}$, and the diffraction patterns were recorded.

\section{Differential Scanning Calorimetry (DSC)}

The samples of PAE monomer, physical mixture, bSLNs and PAE-SLNs were analyzed by differential scanning calorimeter. Using a blank aluminum clamp as a reference, $5 \mathrm{mg}$ of the sample was placed in an aluminum clamp, respectively, nitrogen atmosphere (flow rate: $50 \mathrm{~mL} / \mathrm{min}$ ), scanning temperature range: $30^{\circ} \mathrm{C} \sim 150^{\circ} \mathrm{C}$, scanning rate $10.00^{\circ} \mathrm{C} \mathrm{min}^{-1}$.

\section{Preparation and Characterization of PAE-SLNs-ISG Preparation of PAE-SLNs-ISG}

In this prescription, deacetylation gel with good biocompatibility was used as a gelation matrix to prepare ion-sensitive in situ gel suitable for nasal administration. According to the method described by Hao, ${ }^{17}$ an appropriate amount of DGG was dispersed into distilled water at $90^{\circ} \mathrm{C}$, maintained at this temperature and continuously stirred at $500 \mathrm{rpm}$ for $1 \mathrm{~h}$. After the DGG solution was cooled to room temperature, it was swelled at $4^{\circ} \mathrm{C}$ for $24 \mathrm{~h}$. Under intense stirring, the bioadhesive hydroxypropyl methylcellulose (HPMC) was added to the solution quantitatively and swelled for more than $12 \mathrm{~h}$. The humectant glycerin, antioxidant vitamin $\mathrm{E}$ and preservative chlorinated acetate were added to the solution under stirring, and stored at low temperature.

\section{Response Surface Methodology}

The central composite design (CCD) method was used to study the effect of prescription changes on the properties of in situ gel. The content of DGG determined the response performance and gel strength of the gel, the content of HPMC had a significant effect on the bioadhesive strength of the gel, the content of VG was closely related to the storage stability of the gel solution and the compression resistance of the gel. The independent factors were DGG concentration (A), HPMC concentration (B) and VG concentration (C), solution viscosity (Y1) and gel viscosity (Y2) were selected as two dependent responses. The experiment was designed and evaluated by DesignExpert software (Stat-ease Inc., Minneapolis, MN, US). Table 1 shows the three-factor and five-level $(-1.732,-1$, $0,+1,+1.732)$ full factorial design of the in situ gel matrix. The ideal area of the formulation was established by CCD, and the prescription of PAE-SLNs-ISG was determined. The viscosity was measured at $34^{\circ} \mathrm{C}$. Each group of samples was determined three times in parallel.

\section{Characterization of PAE-SLNs-ISG} Viscosity

The rotary viscometer with a No. 3 rotor was used to measure the viscosity of in situ gel at $60 \mathrm{rpm}$ and the results could be read directly. The measurements were carried out at $34^{\circ} \mathrm{C}$ and run three times in parallel. 
Table I Factors and Levels in the Optimization of PAE-SLNs-ISG

\begin{tabular}{|l|l|l|l|l|l|}
\hline Factor & $\begin{array}{l}\text { Minimum } \\
-1.732\end{array}$ & $\begin{array}{l}\text { Coded Low } \\
-1\end{array}$ & $\begin{array}{l}\text { Mean } \\
\mathbf{0}\end{array}$ & $\begin{array}{l}\text { Coded High } \\
+1\end{array}$ & $\begin{array}{l}\text { Maximum } \\
\mathbf{+ 1 . 7 3 2}\end{array}$ \\
\hline $\begin{array}{l}\text { A: DGG } \\
(\% \mathrm{w} / \mathrm{v})\end{array}$ & 0.2500 & 0.3345 & 0.4500 & 0.5655 & 0.6500 \\
\hline $\begin{array}{l}\text { B: HPMC } \\
(\% \mathrm{w} / \mathrm{v})\end{array}$ & 0.1000 & 0.1845 & 0.3000 & 0.4155 & 0.5000 \\
\hline $\begin{array}{l}\text { C: } \mathrm{VG} \\
(\% \mathrm{w} / \mathrm{v})\end{array}$ & 0.5000 & 0.8170 & 1.2500 & 1.6830 & 2.0000 \\
\hline
\end{tabular}

Abbreviations: PAE-SLNs-ISG, paeonol-solid lipid nanoparticles-in situ gel; DGG, deacetylated gellan gum; HPMC, hydroxypropyl methylcellulose; VG, glycerin.

\section{Critical lonic Concentration (CIC)}

The critical ionic concentration represents the minimum ion concentration to promote the phase transition process, which is a basic parameter that reflects the environmental response performance of the ionic in situ gel. ${ }^{18}$ In order to evaluate the CIC effectively, the gelation time was set to $30 \mathrm{~s}$. The formula of simulated nasal fluid (SNF) was $8.77 \mathrm{~g}$ sodium chloride, $2.98 \mathrm{~g}$ potassium chloride and $0.59 \mathrm{~g}$ calcium chloride dissolved in $1 \mathrm{~L}$ deionized water. One-milliliter ISG solution was placed in an ampoule, and different volumes of SNF were added, gently shaken and mixed, respectively. The gel solution could adhere to the bottom of the bottle without flowing or sliding from the bottle wall within $30 \mathrm{~s}$, indicating that it formed a gel with certain strength and viscosity.

\section{Gel Strength}

Gel strength is an important parameter for evaluating the ability of the polymer to form and maintain gel morphology. ${ }^{19}$ Figure 1B shows the determination scheme of gel strength. An appropriate amount of in situ gel solution was placed in a $100 \mathrm{~mL}$ measuring cylinder, added SNF and shook it gently to form a uniform gel. The quality of the gel was $50 \mathrm{~g}$. The time that the weight $(35 \mathrm{~g})$ sank $5 \mathrm{~cm}$ in the gel could be used to evaluate the gel strength. ${ }^{20}$

\section{Water Retention Capacity}

The evaluation scheme of water retention capacity of the gel was based on the method described by Hosny KM. ${ }^{21}$ One milliliter of in situ gel solution was placed in a centrifuged EP tube which had been accurately weighed, $0.25 \mathrm{~mL}$ SNF was mixed uniformly to form ISG. The quality of the gel was recorded as $\mathrm{M}_{1}$. After centrifuging (6000 rpm) for $15 \mathrm{~min}$, the separated water layer was absorbed with filter paper. The quality of gel was recorded as $\mathrm{M}_{2}$. Water retention capacity $=\mathrm{M}_{2} / \mathrm{M}_{1} * 100 \%$. The tests were carried out at $34^{\circ} \mathrm{C}$ and operated in parallel for three times.

\section{Volume Expansion Coefficient}

The volume expansion coefficient of PAE-SLNs-ISG gel was measured according to the method described by Vidhi Shah. ${ }^{22}$ One milliliter of in situ gel solution was mixed with $250 \mu \mathrm{L}$ of SNF in a graduated tube and the volume $\left(\mathrm{V}_{\mathrm{M}}\right)$ was recorded as $1.25 \mathrm{~mL}$. SNF $(2 \mathrm{~mL})$ was mixed into the gel and the final volume was $\mathrm{V}_{\mathrm{F}}$. The volume of the gel after phase transformation was $\mathrm{V}_{\mathrm{G}}, \mathrm{V}_{\mathrm{G}}=\mathrm{V}_{\mathrm{F}}-2.0$. The experiments were taken at $34^{\circ} \mathrm{C}$ and run in parallel for three times. The expansion coefficient ( $\mathrm{S} \%$ ) of the gel is:

$$
\mathrm{S} \%=\frac{\mathrm{V}_{\mathrm{G}}-\mathrm{V}_{\mathrm{M}}}{\mathrm{V}_{\mathrm{M}}} * 100 \%
$$

\section{$\mathrm{pH}$}

The $\mathrm{pH}$ was obtained directly by a digital $\mathrm{pH}$ meter (INESA PHS-3C, Shanghai, China). The experiments were carried out at $34^{\circ} \mathrm{C}$ and run in parallel for three times.

\section{In vitro Mucoadhesion Strength}

As shown in (Figure 1C), the in vitro mucoadhesion strength was measured according to the improved physical equilibrium method. ${ }^{23}$ Briefly, the nasal mucosa was isolated from the fresh goat nasal cavity and stored in cold PBS ( $\mathrm{pH}$ 7.4), which was used within $6 \mathrm{~h}$. The olfactory mucosa was separated from the nasal cavity and the thickness was $0.6 \mathrm{~mm}$. The nasal mucosa was fixed at the opening of two identical glass bottles (bottle A and bottle B), and the mucosa side was outward, respectively. Bottle A was attached to the balance arm with the bottle mouth down, and bottle B was placed on the support platform. The nasal mucosa of bottle B was uniformly coated with $50 \mathrm{mg}$ of the in situ gel. Adjust the height of the support platform so that the mucosas of bottle A and bottle B all adhered to the in situ gel, and the balance arm was horizontal. The mucosas on both sides were in contact with the in situ gel for $2 \mathrm{~min}$ by an external force. Deionized water was added dropwise to the empty bag until the mucosa was separated from the in situ gel. Measurements were run in parallel for three times. The weight of water resulting in the separation of the mucosa from the gel was recorded as $\mathrm{m}(\mathrm{g})$, the contact area between the mucosa and the gel was recorded as A $\left(\mathrm{cm}^{2}\right)$, and the gravity acceleration $\mathrm{g}$ was $980 \mathrm{~cm} \cdot \mathrm{s}^{-2}$. 
The formula for calculating the in vitro mucoadhesion strength is as follows:

$$
\text { Detachment Stress }=\frac{\mathrm{m} * \mathrm{~g}}{\mathrm{~A}}
$$

\section{Rheology}

The rheological differences between ISG and PAE-SLNsISG were studied by the rheometer (Anton paar MCR302, Graz, Austria). An appropriate amount of sample was filled into the sample cell with a scraper and silicone oil was used to seal the sample cell. The cone-plate gap was set to $0.1 \mathrm{~mm}$. Measurements were made at $34^{\circ} \mathrm{C}$ and operated in parallel for three times.

Rheological curves: Shear stress $\tau(\mathrm{Pa})$ and viscosity $\eta(\mathrm{Pa} \cdot \mathrm{S})$ were recorded under the condition that the range of shear rate $\gamma\left(\mathrm{S}^{-1}\right)$ was $0.01 \sim 1000 \mathrm{~S}^{-1}, \tau=\mathrm{f}(\gamma)$ and $\eta=f(\gamma)$ were plotted.

Stress-strain curves: strain (\%) and modulus $(\mathrm{Pa})$ were recorded under the condition that the scanning range of shear stress $\tau(\mathrm{Pa})$ was $0.01 \sim 100 \mathrm{~Pa}$, strain $(\%)=\mathrm{f}(\tau)$ and modulus $(\mathrm{Pa})=\mathrm{f}(\tau)$ were plotted. The frequency (speed) was set to $10 \mathrm{rad} / \mathrm{s}$.

Frequency scanning curves: modulus $(\mathrm{Pa})$ was recorded in the range of $0 \sim 100 \mathrm{rad} / \mathrm{s}$, and the modulus $(\mathrm{Pa})=\mathrm{f}(\mathrm{Hz})$ was plotted. The loss factor $\tan \delta$ was calculated and $\tan \delta=\mathrm{f}(\mathrm{Hz})$ was plotted. The shear strain was set to $1 \%$.

\section{In vitro Release}

\section{Release of PAE from PAE-SLNs}

The release of PAE from PAE-SLNs was investigated by the dialysis method. Twenty-milligram PAE-SLNs (containing $0.8 \mathrm{mg}$ of PAE) was dissolved in $2 \mathrm{~mL} \mathrm{SNF}$ and put in an activated dialysis bag $(\mathrm{MW}=3500 \mathrm{Da})$. Twentyfive-milliliter SNF was used as the release medium, the oscillation condition was $100 \mathrm{rpm}$. The $\log \mathrm{P}$ of PAE was 2.054. The saturated solubility of PAE in SNF was $0.56 \mathrm{mg} / \mathrm{mL}\left(34^{\circ} \mathrm{C}\right)$. The in vitro release experiment of PAE from PAE-SLNs was consistent with the requirements of leakage condition. Samples were taken at $1 \mathrm{~h}$, $4 \mathrm{~h}, 8 \mathrm{~h}, 12 \mathrm{~h}, 24 \mathrm{~h}, 36 \mathrm{~h}, 48 \mathrm{~h}$ and $72 \mathrm{~h}$ time points for $1 \mathrm{~mL}$, and at the same time, equivalent and isothermal SNF was added. The concentrations of samples were obtained from HPLC to calculate the cumulative release rate of PAE. Measurements were operated three times in parallel at $34^{\circ} \mathrm{C}$.

\section{Release of PAE from PAE-SLNs-ISG}

The release of PAE from PAE-SLNs-ISG was examined by the dialysis method. Ten milligrams of PAE-SLNs (containing $0.4 \mathrm{mg}$ of PAE) was dissolved in $1 \mathrm{~mL}$ of deionized water and mixed with $9 \mathrm{~mL}$ of ISG to obtain PAE-SLNs-ISG. $0.125 \mathrm{~mL}$ SNF was added to $1 \mathrm{~mL}$ PAESLNs-ISG to form a gel. The gel and $2 \mathrm{~mL} \mathrm{SNF}$ were put in a dialysis bag $(\mathrm{MW}=3500 \mathrm{Da})$. Twenty-five-milliliter SNF was used as the release medium, the oscillation condition was $100 \mathrm{rpm}$. Samples were taken at $1 \mathrm{~h}, 4 \mathrm{~h}, 8 \mathrm{~h}$, $12 \mathrm{~h}, 24 \mathrm{~h}, 36 \mathrm{~h}, 48 \mathrm{~h}$ and $72 \mathrm{~h}$ time points for $1 \mathrm{~mL}$, and at the same time, equivalent and isothermal SNF was added. The concentrations of samples were obtained from HPLC to calculate the cumulative release rate of PAE. Measurements were operated three times in parallel at $34^{\circ} \mathrm{C}$.

\section{Release Kinetics}

The release mechanisms of PAE from PAE-SLNs and PAE-SLNs-ISG were studied by using zero-order kinetic model, first-order kinetic model, Higuchi kinetic model and Korsemeyer-Peppa kinetic model. Originpro 8.0 software (OriginLab, Massachusetts, USA) was used for data analysis.

\section{Cell Evaluation}

\section{In vitro Cytotoxicity}

RPMI 2650 cells in the logarithmic growth phase were used for cell experiments. RPMI 2650 cells $\left(5 \times 10^{3}\right)$ were seeded into a 96-well plate. One hundred-microliter serial concentrations $(0.001 \mu \mathrm{g} / \mathrm{mL}, 0.01 \mu \mathrm{g} / \mathrm{mL}, 0.1 \mu \mathrm{g} / \mathrm{mL}$, $1 \mu \mathrm{g} / \mathrm{mL}, 10 \mu \mathrm{g} / \mathrm{mL}, 100 \mu \mathrm{g} / \mathrm{mL}, 1000 \mu \mathrm{g} / \mathrm{mL}$ ) of bSLNs, bSLNs (No removal of free surfactants), PAESLNs, PAE-SLNs (No removal of free surfactants), ISG and PAE-SLNs-ISG were added, respectively, and cultured for $24 \mathrm{~h}$. MTT $(0.5 \mathrm{mg} / \mathrm{mL})$ was applied to each well and incubated at $37^{\circ} \mathrm{C}$ for $2 \mathrm{~h}$. After the culture was terminated, the culture solution in the pore was carefully sucked out and DMSO $(200 \mu \mathrm{L})$ was applied to each pore. The purple crystal (intracellular formazan salt) was fully dissolved in the absence of light. The optical density of the solution in each pore was measured using a microplate reader (RAD iMark, Bio-Rad, USA) at a wavelength of $492 \mathrm{~nm}$ and the cell viability was calculated.

\section{Live/Dead Double Staining Method}

RPMI 2650 cells in the logarithmic growth phase were used for cell experiments. RPMI 2650 cells $\left(5 \times 10^{3}\right)$ were 
seeded into a 96-well plate. One hundred microliters of $1000 \mu \mathrm{g} / \mathrm{mL}$ of bSLNs, bSLNs (No removal of free surfactants), PAE-SLNs, PAE-SLNs (No removal of free surfactants), ISG and PAE-SLNs-ISG were added, respectively, and cultured for $24 \mathrm{~h}$. Sample cells were collected and the number of cells was within $1 \times 10^{6}$. After washing twice with PBS, the cells were resuspended in $200 \mu \mathrm{L}$ of Calcein-AM/PI staining solution and incubated at $4^{\circ} \mathrm{C}$ for $15 \sim 30 \mathrm{~min}$ in the dark. The cells were washed twice with PBS and resuspended, and observed under a Confocal Microscope (DM6000 B, LEICA, DEU). Under a Confocal Microscope, the living cells were yellow and the dead cells were red when excited at $490 \mathrm{~nm}$ wavelength. At the excitation wavelength of $545 \mathrm{~nm}$, only red dead cells could be seen. All samples were tested in triplicate.

\section{Flow Cytometry}

RPMI 2650 cells in the logarithmic growth phase were used for cell experiments. RPMI 2650 cells $\left(1 \times 10^{5}\right)$ were seeded into a 6 -well plate. The culture solution was discarded. The serum-free culture solution containing $100 \mu \mathrm{g} / \mathrm{mL}$ of FITC-SLNs was added and the culture was continued for $1 \mathrm{~h}, 4 \mathrm{~h}$, and $6 \mathrm{~h}$. After discarding the culture solution, the cells were washed with PBS and the supernatant was discarded. One milliliter of $0.25 \%$ trypsin was added to digest the cells, when the cells became round and some of them were suspended, PBS was added to terminate the digestion. A pipette was used to gently blow the cells and suspend them. The cell suspension was transferred into a centrifuge tube and centrifuged at $1500 \mathrm{rpm}$ for $5 \mathrm{~min}$ at low temperature. The cells were suspended in PBS, 10,000 cells were collected to measure the fluorescence intensity, and the $\mathrm{X}$-mean value was used to evaluate the time dependence of the cellular uptake of nanoparticles by Flow Cytometry (FACSVerse, Becton, Dickinson and Company, USA).

\section{In vivo Evaluation}

\section{Real-Time Biodistribution}

Twelve male nude mice were randomly divided into two groups and fasted for $12 \mathrm{~h}$ before the experiment. One group was given $50 \mu \mathrm{L}$ of Cy7-SLNs-ISG in unilateral nasal cavity by using the self-made applicator $(0.5 \mathrm{~cm}$ deep into the nasal cavity), and the other group was injected with $200 \mu \mathrm{L}$ of Cy7-SLNs physiological saline solution of the same content in the tail vein. After gas anesthesia at $5 \mathrm{~min}, 30 \mathrm{~min}, 1 \mathrm{~h}, 2 \mathrm{~h}$ and $4 \mathrm{~h}$, respectively, the nude mice were observed in a supine position on the living imager (IVIS Lumina II, Calipera, USA). The software-controlled imaging dark box platform was raised and lowered to a suitable field of vision, and the lights turned on automatically (bright field) to take the first background picture. The lights turned off automatically, and the fluorescence (Ex/Em:749 nm/767 nm) emitted from the nude mice was photographed in the absence of an external light source (dark field). The position and intensity of fluorescence in nude mice were observed intuitively by the superposition of bright field and dark field. After the in vivo imaging experiment, the two groups of nude mice were anesthetized with chloral hydrate solution $(400 \mathrm{mg} / \mathrm{kg})$, and then the chest cavity was quickly opened to expose the heart. The heart was perfused with normal saline, washed until the clear liquid flowed out, and fixed with precooled $4^{\circ} \mathrm{C}$ polyformaldehyde. The nude mice were decapitated and the whole brain was taken by cutting the cranium along the middle line of the skull, and the heart, liver, spleen, lung and kidney organs were also obtained. The organs were placed on the platform of the imaging dark box and the fluorescence response of each organ was observed.

\section{Brain Area Distribution}

Five male SD rats $(200 \pm 20 \mathrm{~g})$ were fasted for $12 \mathrm{~h}$ before the experiment. The rats were given $50 \mu \mathrm{L}$ of Cy7-SLNsISG in the unilateral nasal cavity by using the self-made applicator $(0.5 \mathrm{~cm}$ deep into the nasal cavity). After $2 \mathrm{~h}$, the rats were anesthetized intraperitoneally with chloral hydrate solution $(400 \mathrm{mg} / \mathrm{kg})$, and then the chest cavity was quickly opened to expose the heart. The heart was perfused with normal saline, washed until the clear liquid flowed out, and fixed with precooled $4^{\circ} \mathrm{C}$ polyformaldehyde. The rats were decapitated, and the cranium was cut along the middle line of the skull. The brain tissue samples were quickly placed in normal saline to remove the blood or content, and then imprinted on the filter paper. The samples were embedded in Oct paraffin and frozen in isopentane for $1 \mathrm{~min}$ at $-80^{\circ} \mathrm{C}$. The samples were rewarming at $-20^{\circ} \mathrm{C}$ for $30 \mathrm{~min}$ before sectioning, and the sagittal sections were made with a thickness of $10 \mu \mathrm{m}$. The observed brain areas included striatum, substantia nigra, cerebellum and olfactory bulb. The sections were stained with DAPI (Blue, Ex/Em: $358 \mathrm{~nm} / 461 \mathrm{~nm}$ ), and sealed with fluorescence anti-quenching agent after washing with PBS for three times, and then observed under Confocal 
Microscope (DM6000 B, LEICA, DEU) to record the distribution of Cy7-SLNs (Ex/Em: $749 \mathrm{~nm} / 767 \mathrm{~nm}$ ) in the brain region.

\section{Statistics Analysis}

All data are expressed as average \pm standard deviation (SD). The differences between groups were performed using Student's $t$-test or one-way analysis of variance (ANOVA). ${ }^{*} \mathrm{p}<0.05, * * \mathrm{p}<0.001$ and $* * * \mathrm{p}<0.0001$ were considered statistically significant.

\section{Results and Discussion}

\section{Stability of PAE in Simulated Biological Samples}

Studies on the metabolic stability and mechanism of drugs in artificial gastric juice, artificial intestinal juice and in vitro liver microsomes are helpful to evaluate the adaptability of oral or intravenous administration of drugs, and provide a basis for the choice of administration routes and formulations. $^{24}$ The metabolic stabilities of PAE in different simulated biological samples are shown in (Figure 2). The metabolic rate of the artificial gastric juice group was higher than that of the blank gastric juice group; the metabolic rate of the artificial intestinal juice group was higher than that of the blank intestinal juice group, indicating that pepsin and trypsin were involved in the metabolism of PAE in the gastrointestinal tract. After incubation for $6 \mathrm{~h}$, the metabolic residual contents of PAE in blank gastric juice and artificial intestinal juice were $74.11 \% \pm 2.52 \%$ and $93.29 \% \pm 1.79 \%$, respectively, indicating that the metabolism of PAE was $\mathrm{pH}$-dependent. Compared with the effects of pepsin and trypsin on the metabolism of PAE, $\mathrm{pH}$ was a more important factor. After incubation for $1 \mathrm{~h}$, both the metabolic residual contents of PAE in blank gastric juice and artificial gastric juice were higher than $90 \%$. After incubation for $4 \mathrm{~h}$, both the metabolic residual contents of PAE in blank intestinal juice and artificial intestinal juice were higher than $90 \%$.

The hepatic first-pass effect of drugs can be initially evaluated by the liver microsomes metabolic system in vitro. $^{25}$ As shown in Figure $2 \mathrm{C}$, the metabolism of PAE was extremely rapid in the liver microsomes metabolism system (liver microsomes + NADPH), and the metabolic residual content at $30 \mathrm{~min}$ was only $20.97 \% \pm 2.99 \%$. The metabolism of PAE in the blank liver microsomes (without NADPH) was significantly lower than that in the liver microsomes metabolic system. The metabolic type of
PAE in the liver was mainly Phase I metabolism, and the main metabolites were 2, 4-dihydroxyacetophenone and four kinds of oxidative metabolites. ${ }^{26}$ Reduced nicotinamide adenine dinucleotide phosphate (NADPH) is an indispensable auxiliary factor in the biotransformation of many compounds, which is involved in the reaction of CYP450 enzymes, FMOs enzymes and other oxidases in liver microsomes. ${ }^{27}$

The metabolic mechanisms of PAE in different simulated biological samples are shown in Table 2. The metabolic mechanisms of PAE in artificial gastric juice, blank gastric juice, artificial intestinal juice, blank intestinal juice and liver microsomes were first-order kinetics. The metabolic mechanism of PAE in blank liver microsomes was not matched with zero-order kinetics or first-order kinetics, which might be related to enzymatic activity and the saturation effect. The metabolic half-life of PAE in liver microsomes was only $0.23 \mathrm{~h} \pm 0.03 \mathrm{~h}$, and the hepatic firstpass effect was significant. The metabolic half-lives of PAE in artificial gastric juice $(10.49 \mathrm{~h} \pm 0.27 \mathrm{~h})$ and artificial intestinal juice $(31.08 \mathrm{~h} \pm 0.32 \mathrm{~h})$ were 45 times and 135 times of that in liver microsomes, respectively.

The metabolic stability of PAE in simulated biological samples indicated that the hepatic first-pass effect of PAE was obvious, and PAE was not suitable for direct oral. As a neuroprotective agent for the treatment of central nervous system diseases, PAE should be protected by nanoencapsulation technology or administered by non-oral or non-venous route to increase the accumulation of it in brain regions. The brain area delivery of PAE based on nose-brain transport pathway is a potentially feasible strategy.

\section{Preparation and Characterization of PAE-SLNs Encapsulation Efficiency}

The encapsulation efficiency of PAE-SLNs was $88.72 \% \pm$ $2.13 \%$ determined by ultrafiltration. The encapsulation efficiency of solid lipid nanoparticles was affected by the solubility and dispersion of drugs in the matrix and the phase state of the lipid. ${ }^{28}$ PAE was a lipid-soluble drug, which could be well dissolved and dispersed in the mixed lipid matrix of glycerol monostearate and soybean lecithin. The $\mathrm{O} / \mathrm{W}$ colostrum formed after high-temperature emulsification could form uniform liquid lipid nanoparticles by ultrasonic dispersion and the dispersion of PAE in the liquid lipid matrix was increased. This was beneficial to 


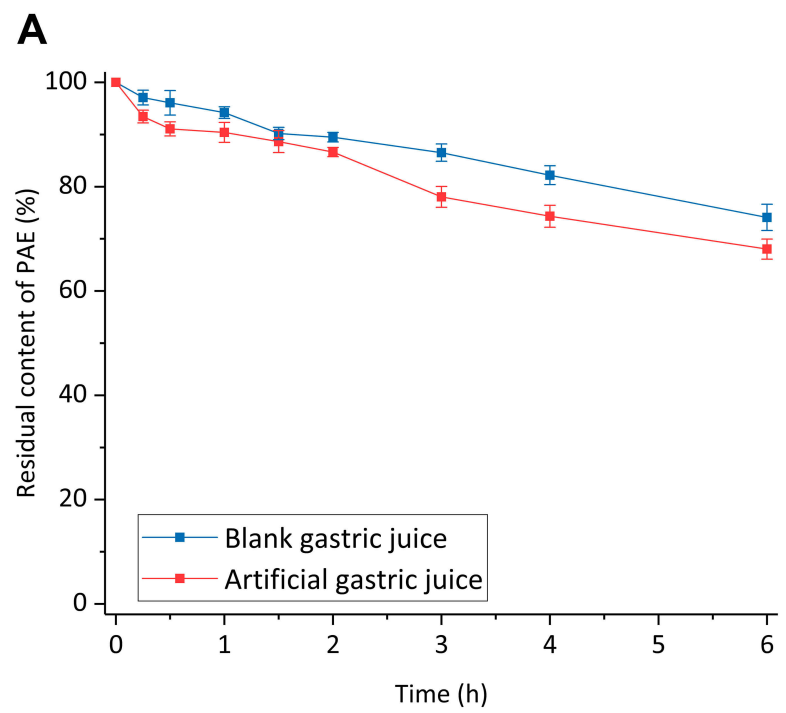

B
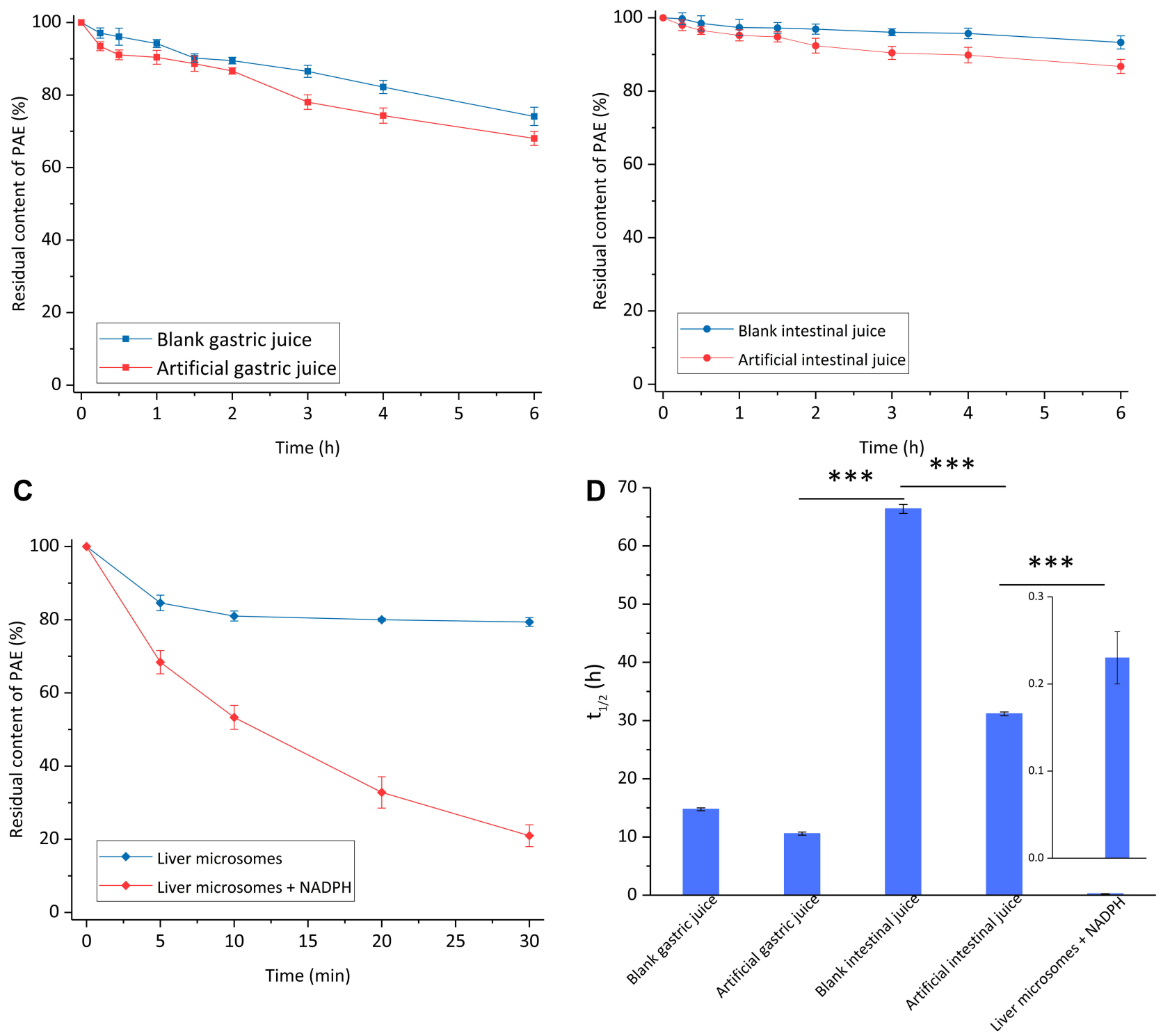

Figure 2 Stability of PAE in simulated biological samples. (A) Stability of PAE in artificial gastric juice; (B) stability of PAE in artificial intestinal juice; (C) stability of PAE in the liver microsomes metabolic system in vitro; (D) first-order metabolic half-lives of PAE in different simulated biological samples. Data are expressed as mean \pm SD, $n=3$. Notes: The differences between groups were performed using Student's $t$-test or one-way analysis of variance (ANOVA). $* * * p<0.000$ I was considered statistically significant.

Abbreviations: PAE, paeonol; NADPH, nicotinamide adenine dinucleotide phosphate.

the rapid curing of liquid lipid nanoparticles in the process of low temperature curing to seal the drug, prevent drug leakage and increase the entrapment efficiency.

\section{Particle Size and Zeta Potential}

The average particle sizes of bSLNs, PAE-SLNs, FITC-SLNs and Cy7-SLNs were $123.78 \mathrm{~nm} \pm 1.30 \mathrm{~nm}, 166.79 \mathrm{~nm} \pm 2.92$ $\mathrm{nm}, 152.51 \mathrm{~nm} \pm 2.51 \mathrm{~nm}$ and $142.27 \mathrm{~nm} \pm 3.72 \mathrm{~nm}$, respectively, which were consistent with the particle size requirements of nanomedicine. The particle size distribution ranges of bSLNs, PAE-SLNs, FITC-SLNs and Cy7-SLNs were all concentrated relatively, indicating that the sizes of the nanoparticles were relatively uniform. The particle size of PAE-SLNs was larger than that of bSLNs, which indirectly indicated that PAE was loaded successfully. The particle size of FITC-SLNs was lower than that of PAE-SLNs, which may be related to the difference in melting point. In the process of low-temperature curing, high melting point substances could quickly solidify in the lipid core to form smaller solid lipid nanoparticles. $^{29}$ 
Table 2 Metabolic Mechanisms of Paeonol

\begin{tabular}{|l|l|l|l|l|}
\hline Simulated Biological Samples & Model & $\mathbf{k}$ & $\mathbf{t}_{\mathbf{I} / \mathbf{2}}(\mathbf{h})$ & $\mathbf{R}^{\mathbf{2}}$ \\
\hline Blank gastric juice & First order dynamics & 0.0470 & $14.74 \pm 0.24$ & $y=-0.0470 x+4.5913$ \\
Artificial gastric juice & First order dynamics & 0.0609 & $10.49 \pm 0.27$ & $y=-0.0609 x+4.5669$ \\
Blank intestinal juice & First order dynamics & 0.0104 & $66.63 \pm 1.21$ & $y=-0.0104 x+4.5977$ \\
Artificial intestinal juice & First order dynamics & 0.0223 & $31.08 \pm 0.32$ & $y=-0.0223 x+4.5852$ \\
Liver microsomes & First order dynamics & 0.0507 & $0.23 \pm 0.03$ & $y=-0.0507 x+4.5277$ \\
\hline
\end{tabular}

Zeta potential has an important influence on the physical stability and cytocompatibility of the colloidal dispersion system. The zeta potentials of bSLNs, PAE-SLNs, FITC-SLNs and Cy7-SLNs were $-8.74 \mathrm{mV} \pm 0.30 \mathrm{mV}$, $-8.69 \mathrm{mV} \pm 0.21 \mathrm{mV},-11.45 \mathrm{mV} \pm 0.21 \mathrm{mV}$ and -11.77 $\mathrm{mV} \pm 0.45 \mathrm{mV}$, respectively. High zeta potential could increase the electrostatic repulsion between nanoparticles and prevent the aggregation of charged particles, but the excessive zeta negative potential could also increase the electrostatic repulsion between the nanoparticles and the cell membrane and then inhibit cellular uptake. ${ }^{30}$

The polydispersity indexes of bSLNs, PAE-SLNs, FITC-SLNs and Cy7-SLNs were $0.223 \pm 0.021,0.241 \pm$ $0.030,0.243 \pm 0.028$ and $0.238 \pm 0.019$, respectively. Good polydispersity was beneficial to the physical stability of nanoparticles.

\section{Transmission Electron Microscopy (TEM)}

The surface topography of PAE-SLNs was observed by TEM. As shown in Figure 3A, PAE-SLNs were polyhedral or spherical particles with good dispersion and the range of particle size were $100 \mathrm{~nm} \sim 150 \mathrm{~nm}$. The particle size observed by TEM was smaller than that by DLS, the reason was related to the test method. The particle size determined by DLS was the addition of nanoparticles and the surrounding hydration layer. The morphology of nanoparticles can affect the uptake of cells, and the order is: sphere $>$ cube $>$ rod $>$ disk. ${ }^{31}$

\section{Fourier Transform Infrared Spectrum (FTIR)}

(Figure 3B) shows the infrared spectra of PAE monomer, physical mixture, bSLNs and PAE-SLNs. In the infrared curve of PAE, the wide peak at $3065.27 \mathrm{~cm}^{-1}$ was the stretching vibration of phenolic hydroxyl group; the absorption peak at $1622.45 \mathrm{~cm}^{-1}$ was the stretching vibration of aryl ketone carbonyl group, which moved to a low wavenumber due to the conjugated action of benzene ring and carbonyl group. The strong absorption peak at $1250.65 \mathrm{~cm}^{-1}$ was the stretching vibration of $\mathrm{C}-\mathrm{O}$ in aromatic ether; the stretching vibration appearing in 1650 $\sim 1430 \mathrm{~cm}^{-1}$ was caused by benzene ring. In the infrared spectra of physical mixture, bSLNs and PAE-SLNs, the two absorption peaks at around $2852 \mathrm{~cm}^{-1}$ and $2926 \mathrm{~cm}^{-1}$ proved the existence of $-\mathrm{CH}_{2}-$. The stretching vibration of carbonyl group at about $1740 \mathrm{~cm}^{-1}$ and the stretching vibration of C-O-C at $1150 \sim 1200 \mathrm{~cm}^{-1}$ were the characteristic absorption peaks of esters. The infrared spectrum of PAE-SLNs was similar to that of the physical mixture, indicating that there was no old chemical bond breaking or new chemical bond formation in the formation of PAESLNs. There was no chemical interaction between the drug and the excipients, and the drug loading form of PAE was a physical loading. The characteristic peaks of PAE in the physical mixture and PAE-SLNs were not obvious, which may be related to the low content of PAE in the prescription.

\section{X-Ray Diffraction Analysis (XRD)}

The X-ray diffraction patterns of PAE, physical mixture, bSLNs and PAE-SLNs are shown in Figure 3C. The XRD of PAE revealed the distinct peaks at $2 \theta: 11.86^{\circ}, 13.46^{\circ}$, $16.46^{\circ}, 16.94^{\circ}, 18.58^{\circ}, 21.10^{\circ}, 23.38^{\circ}, 23.74^{\circ}, 24.24^{\circ}$, $24.64^{\circ}, 25.62^{\circ}, 27.50^{\circ}$ and $48.38^{\circ}$. The physical mixture showed the peaks at $2 \theta: 9.66^{\circ}, 11.72^{\circ}, 16.42^{\circ}, 16.94^{\circ}$, $18.58^{\circ}, 21.10^{\circ}, 23.38^{\circ}, 23.74^{\circ}, 24.24^{\circ}, 24.64^{\circ}, 25.62^{\circ}$, $27.50^{\circ}$ and $48.38^{\circ}$. The bSLNs showed the peaks at $2 \theta$ : $9.76^{\circ}, 17.26^{\circ}, 20.46^{\circ}, 21.22^{\circ}, 22.18^{\circ}, 24.72^{\circ}, 25.34^{\circ}$, $28.00^{\circ}, 36.22^{\circ}$ and $44.98^{\circ}$. The PAE-SLNs showed the peaks at $2 \theta: 9.60^{\circ}, 20.34^{\circ}, 21.08^{\circ}, 22.02^{\circ}, 24.58^{\circ}$, $25.22^{\circ}, 27.82^{\circ}, 36.08^{\circ}$ and $44.84^{\circ}$. The sharp peak of PAE proved its good crystallinity. The diffraction characteristic peak of PAE appeared in the physical mixture, which proved that PAE still existed in the form of crystal. The characteristic peak of PAE disappeared in PAE-SLNs, indicating that PAE changed from crystal state to amorphous or molecular state and dispersed in the lipid matrix, which was consistent with the results of FTIR and DSC. The diffraction patterns of bSLNs and PAE-SLNs were 


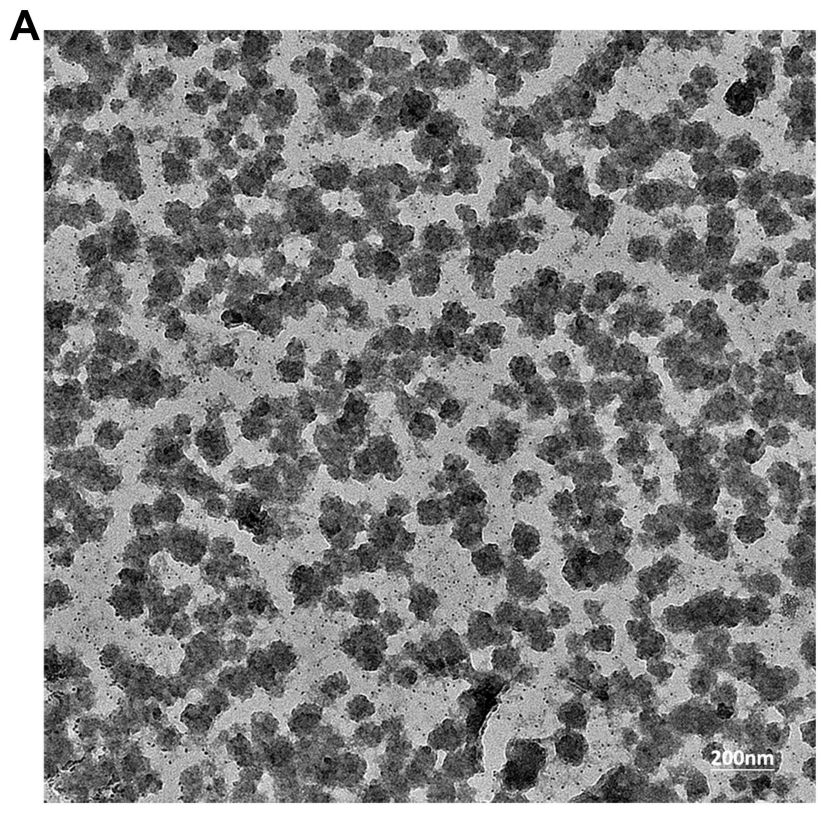

B

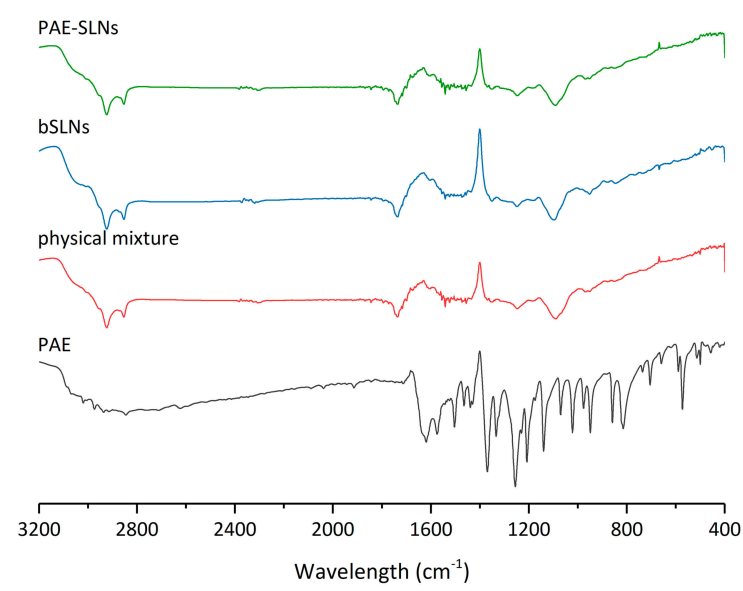

D

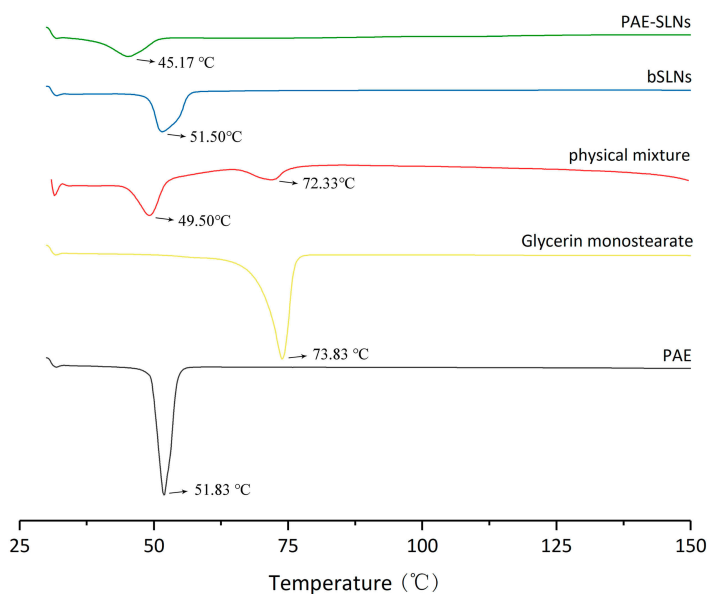

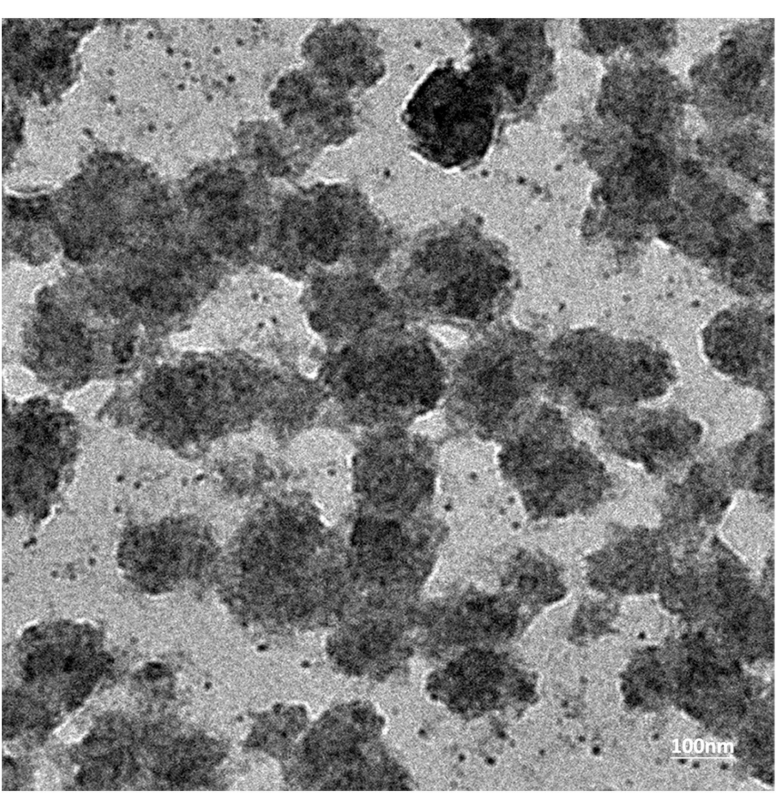

C

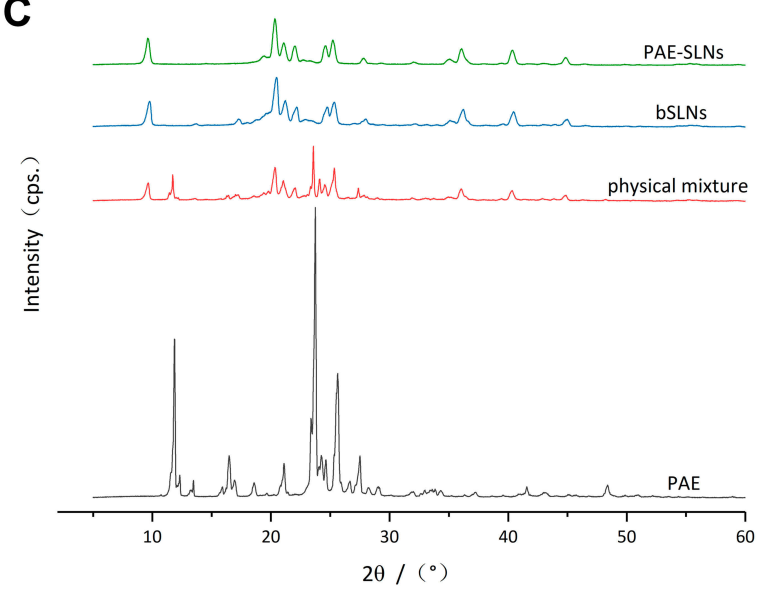

$\mathbf{E}$

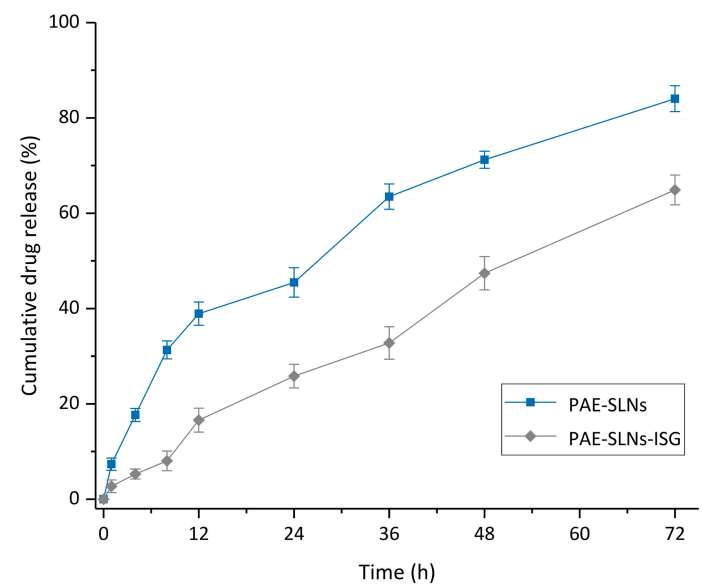

Figure 3 (A) Transmission electron microscopy (TEM) images of PAE-SLNs. (B) Fourier transform infrared spectrum (FTIR) spectra of PAE, physical mixture, bSLNs and PAE-SLNs. (C) X-ray diffraction (XRD) patterns of PAE, physical mixture, bSLNs and PAE-SLNs. (D) Differential scanning calorimetry (DSC) thermographs of PAE, glycerin monostearate, physical mixture, bSLNs and PAE-SLNs. (E) In vitro release curves of PAE-SLNs and PAE-SLNs-ISG in SNF ( $34^{\circ} \mathrm{C}$ ) over $72 \mathrm{~h}$. Data are expressed as mean \pm $\mathrm{SD}, \mathrm{n}=3$

Abbreviations: PAE, paeonol; PAE-SLNs, paeonol-solid lipid nanoparticles; PAE-SLNs-ISG, paeonol-solid lipid nanoparticles-in situ gel; bSLNs, blank solid lipid nanoparticles; SNF, simulated nasal fluid. 
similar, which showed that the doping of PAE in the lipid matrix had little effect on the morphology of SLNs.

\section{Differential Scanning Calorimetry (DSC)}

The thermal behaviors of PAE, glyceryl monostearate, physical mixture, bSLNs and PAE-SLNs were studied by differential scanning calorimetry (DSC), and the results are shown in Figure 3D. $51.83^{\circ} \mathrm{C}$ and $73.83^{\circ} \mathrm{C}$ corresponded to the melting point of PAE and glyceryl monostearate, respectively, and the melting peaks of both were sharp, indicating that the two substances had complete lattice structure. There was only one melting peak in bSLNs, indicating that the excipients formed nanocomposites through physical interaction. The melting peak of PAE disappeared in PAE-SLNs, indicating that PAE in PAE-SLNs changed from crystal state to amorphous or molecular state. The melting point of PAESLNs $\left(45.17^{\circ} \mathrm{C}\right)$ moved to a lower temperature than the two melting peaks in the physical mixture $\left(49.50^{\circ} \mathrm{C}, 72.33^{\circ} \mathrm{C}\right)$ and the melting peak in bSLNs $\left(51.50^{\circ} \mathrm{C}\right)$, this was because the dispersion of PAE in the lipid matrix increased the randomness of PAE-SLNs and decreased the Gibbs free energy of the lipid lattice. The melting enthalpy of solid substance was also directly related to the particle size. The higher surface energy of nanoparticles could form an energy suboptimal state, resulting in the "Gibbs-Thomson effect" or "Small size effect" and leading to the decrease in the melting point of lipids. ${ }^{32}$

\section{Preparation and Characterization of PAE-SLNs-ISG \\ Response Surface Methodology}

Deacetylated gellan gum is a typical ionic sensitive gel matrix with good nasal compatibility. ${ }^{33}$ The abundant cations in the nasal mucus produced electrostatic shielding effect on the molecular chain, the double helix dimer of DGG molecule was polymerized and crosslinked to form a three-dimensional network structure by hydrogen bonding. ${ }^{34}$ If DGG was used as the only matrix of in situ gel, although it had high gelation responsiveness and gel strength, its surface was easy to form a hydration layer, which was easy to be cleaned out of the nasal cavity. The nasal mucosa was negatively charged and positively charged drugs, polymer materials or preparations could be firmly bonded to the nasal mucosa. ${ }^{35}$ HPMC with low molecular weight was an effective biological adhesive, the hydrogen bonds formed by hydroxyl groups in HPMC and water in nasal mucus could enhance the mucosal adhesion and nasal retention time of the gel. ${ }^{36}$ The three hydroxyl groups of glycerol could form hydrogen bonds with water molecules in the gel to avoid the dehydration of gel when stored and subjected to strong external forces. ${ }^{37}$

The experimental design and results of CCD are shown in Table 3. The effects of changes in the contents of DGG, HPMC and VG on Y1 and Y2 are shown in Figure 4. The empirical relationships between $\mathrm{X}$ and $\mathrm{Y}$ were consistent with the Quadratic model (Table 4). The $\mathrm{R}^{2}$ value of $\mathrm{Y} 1$ fitting equation was 0.98 and the $\mathrm{R}^{2}$ value of $\mathrm{Y} 2$ fitting equation was 0.96 . The ideal fitting equation could be used to describe and predict the relationship between independent variables and responses. With the increase of DGG concentration (A), HPMC concentration (B) and VG concentration (C), Solution Viscosity (Y1) and Gel Viscosity (Y2) increased. DGG concentration (A) and HPMC concentration (B) had greater effects on Solution Viscosity (Y1) and Gel Viscosity (Y2) than VG concentration (C). The influence of independent variables on Gel Viscosity (Y2) was higher than that on Solution Viscosity (Y1).

The nasal cilia swing from the nasal cavity to the pharynx at a frequency of 1000 times/min (about $17 \mathrm{~Hz}$ ), the mucus blanket formed by the nasal mucus moves with it, and generally, foreign bodies can be removed to the pharynx in 10-15 min. ${ }^{38}$ Foreign bodies then enter the digestive tract and are excreted out of the body, this clearance mechanism is an important form of nasal protection mechanism. Nasal preparations need to have a certain viscosity and strength to resist the removal of nasal cilia. ${ }^{39}$ However, if the viscosity and strength of the preparation are too high, it will cause irreversible physiological damage to nasal cilia and nasal mucosa, and destroy the integrity of nasal physiological function. ${ }^{40}$ In order to ensure the adaptability of nasal preparations for nasal administration, the viscosity of in situ gel after gelation should be controlled within a certain range. In addition, the viscosity of in situ gel in solution state is directly related to the accuracy and compliance of nasal administration, so it is also required to be controlled within a certain range. The ranges of target values of Solution Viscosity (Y1) and Gel Viscosity (Y2) are shown in (Figure 4G and H), and the ranges of possible values of DGG concentration (A), HPMC concentration (B) and VG concentration (C) are shown in Figure 4I. According to the optimized results, the formulation of PAE-SLNs-ISG was formulated, and the results are shown in Table 5.

\section{Characterization of ISG and PAE-SLNs-ISG}

The key condition of nasal administration adaptability of in situ gel preparations is gelation ability, that is, the 
Table 3 Central Composite Design Experiments and Experimental Results

\begin{tabular}{|c|c|c|c|c|c|}
\hline Runs & $\begin{array}{l}\text { Factor I } \\
\text { A: DGG } \\
(\% w / v)\end{array}$ & $\begin{array}{l}\text { Factor } 2 \\
\text { B: HPMC } \\
(\% w / v)\end{array}$ & $\begin{array}{l}\text { Factor } 3 \\
\text { C: VG } \\
(\% \mathrm{w} / \mathrm{v})\end{array}$ & $\begin{array}{l}\text { Response I } \\
\text { Solution Viscosity } \\
\mathrm{mPa}\end{array}$ & $\begin{array}{l}\text { Response } 2 \\
\text { Gel Viscosity } \\
\mathrm{mPa}\end{array}$ \\
\hline I & 0.3345 & 0.1845 & 0.8170 & $27.40 \pm 0.39$ & $904.37 \pm 10.49$ \\
\hline 2 & 0.5655 & 0.1845 & 0.8170 & $461.20 \pm 3.25$ & $|288.4| \pm 9.4 \mid$ \\
\hline 3 & 0.3345 & 0.4155 & 0.8170 & $86.77 \pm 0.82$ & $1000.98 \pm 11.49$ \\
\hline 4 & 0.5655 & 0.4155 & 0.8170 & $994.07 \pm 7.12$ & $1763.26 \pm 21.44$ \\
\hline 5 & 0.3345 & 0.1845 & 1.6830 & $22.83 \pm 0.11$ & $902.25 \pm 17.29$ \\
\hline 6 & 0.5655 & 0.1845 & 1.6830 & $362.30 \pm 2.47$ & $1795.40 \pm 30.48$ \\
\hline 7 & 0.3345 & 0.4155 & 1.6830 & $126.37 \pm 1.07$ & $1453.09 \pm 16.39$ \\
\hline 8 & 0.5655 & 0.4155 & 1.6830 & $822.00 \pm 6.33$ & $1955.85 \pm 22.20$ \\
\hline 9 & 0.2500 & 0.3000 & 1.2500 & $73.07 \pm 0.09$ & $846.51 \pm 13.84$ \\
\hline 10 & 0.6500 & 0.3000 & 1.2500 & $914.87 \pm 5.59$ & $1955.82 \pm 19.22$ \\
\hline II & 0.4500 & 0.1000 & 1.2500 & $86.77 \pm 0.11$ & $|20| .58 \pm 23.04$ \\
\hline 12 & 0.4500 & 0.5000 & 1.2500 & $535.83 \pm 2.37$ & $|722.9| \pm 21.89$ \\
\hline 13 & 0.4500 & 0.3000 & 0.5000 & $200.90 \pm 0.92$ & $1412.05 \pm 13.90$ \\
\hline 14 & 0.4500 & 0.3000 & 2.0000 & $202.43 \pm 1.20$ & $1904.54 \pm 26.77$ \\
\hline 15 & 0.4500 & 0.3000 & 1.2500 & $207.50 \pm 0.42$ & $1951.40 \pm 20.16$ \\
\hline 16 & 0.4500 & 0.3000 & 1.2500 & $205.21 \pm 1.38$ & $1955.24 \pm 18.53$ \\
\hline 17 & 0.4500 & 0.3000 & 1.2500 & $205.23 \pm 1.22$ & $1957.49 \pm 19.36$ \\
\hline 18 & 0.4500 & 0.3000 & 1.2500 & $209.01 \pm 2.03$ & $1949.27 \pm 20.66$ \\
\hline 19 & 0.4500 & 0.3000 & 1.2500 & $207.28 \pm 0.91$ & $1955.04 \pm 18.30$ \\
\hline 20 & 0.4500 & 0.3000 & 1.2500 & $207.31 \pm 0.62$ & $|958.38 \pm 25.0|$ \\
\hline
\end{tabular}

Abbreviations: DGG, deacetylated gellan gum; HPMC, hydroxypropyl methylcellulose; VG, glycerin.

degree and speed of the gel phase transition. ${ }^{41}$ After the nasal administration of in situ gel, if the phase transition rate is too slow, the semisolid state of the preparation is too long, the drug or nanoparticles can diffuse rapidly from the gel and cause burst drug release. After mixing $1 \mathrm{~mL}$ of ISG and PAE-SLNs-ISG with $125 \mu \mathrm{L}$ of SNF, respectively, the gel could be formed rapidly within $30 \mathrm{~s}$. The gelation time and critical ion concentration were consistent with the requirements of nasal administration. A low requirement of critical ion concentration can increase the adaptability of the gel to the fluctuation of nasal physiological state, and at the same time, the rapid gelation at the position of administration can prevent the change of absorption position.

The two most important indexes of gel degree are viscosity and strength. Appropriate viscosity and strength can ensure the retention of gel in the administration position for a long time, increase the nasal absorption time, improve the nasal absorption efficiency, and then improve the nose-brain transport efficiency. ${ }^{42}$ The solution viscosities of ISG and PAE-SLNs-ISG were $151.27 \mathrm{mPa} \cdot \mathrm{S} \pm 1.61 \mathrm{mPa} \cdot \mathrm{S}$ and $144.36 \mathrm{mPa} \cdot \mathrm{S} \pm 2.89 \mathrm{mPa} \cdot \mathrm{S}$, respectively. The gel viscosities of ISG and PAE-SLNs-ISG were 1638.32 $\mathrm{mPa} \cdot \mathrm{S} \pm 22.91 \mathrm{mPa} \cdot \mathrm{S}$ and $1542.19 \mathrm{mPa} \cdot \mathrm{S} \pm 19.30$
$\mathrm{mPa} \cdot \mathrm{S}$, respectively. The viscosities of both ISG and PAESLNs-ISG increased significantly after gelation $(* * * \mathrm{p}<$ 0.0001). The viscosity of PAE-SLNs-ISG in solution state was lower than that of ISG because the dilution effect of PAE-SLNs colloid solution mixed with ISG reduced the viscosity of the system. The viscosity of PAE-SLNs-ISG in the gel state was lower than that of ISG because the incorporation of PAE-SLNs had an effect on the crosslinking of DGG. It was worth noting that there was no significant difference in the viscosities of both ISG and PAE-SLNs-ISG in solution and gel state, indicating that the incorporation of PAE-SLNs had little effect on the adaptability of nasal administration of ISG. The gel strengths of ISG and PAE-SLNs-ISG were $29 \mathrm{~s} \pm 2 \mathrm{~s}$ and $24 \mathrm{~s} \pm 1 \mathrm{~s}$, respectively, and there was no significant difference. It is generally believed that the gel strength of nasal preparations in $20 \mathrm{~s} \sim 50 \mathrm{~s}$ can effectively maintain the integrity of gel without affecting the gel retention in the nasal cavity for a long time. ${ }^{43}$

The water retention capacity can be used to evaluate the storage and transport stability of the gel. ${ }^{44}$ The water retention capacities of ISG and PAE-SLNs-ISG were $97.23 \% \pm 0.79 \%$ and $95.40 \% \pm 1.17 \%$, respectively, which had good preparation stability. The limited volume 
A

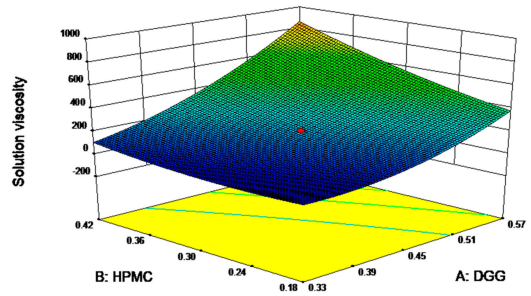

a

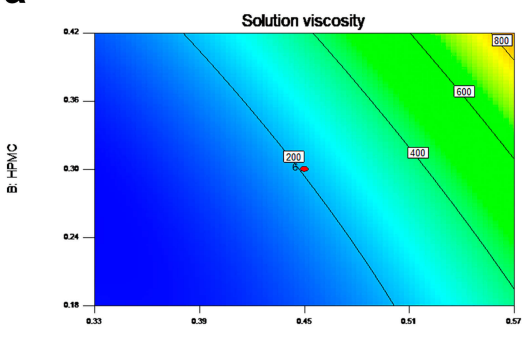

D

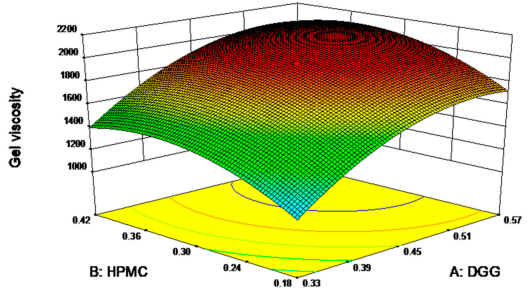

d

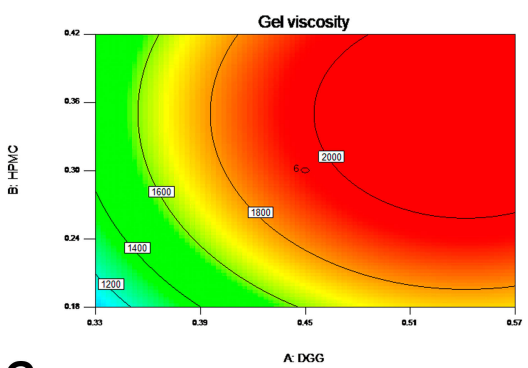

G

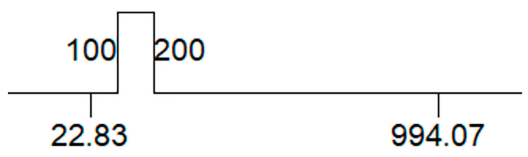

B

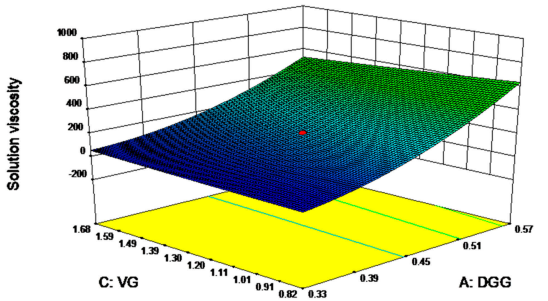

b

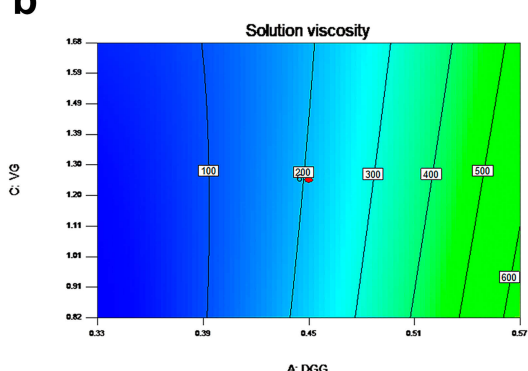

E

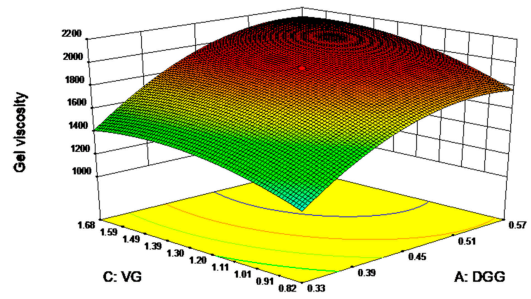

e

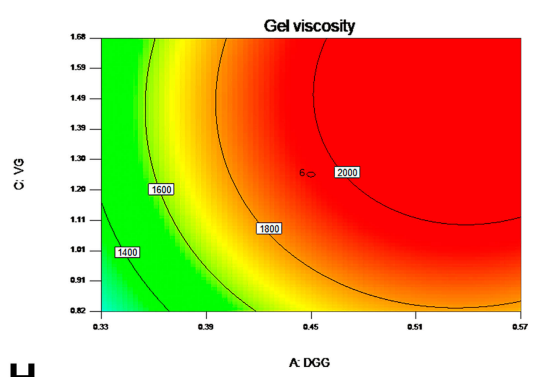

H

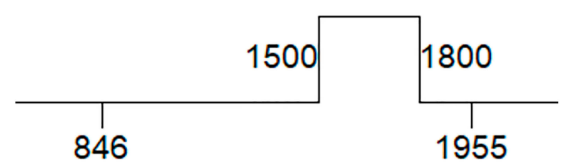

C

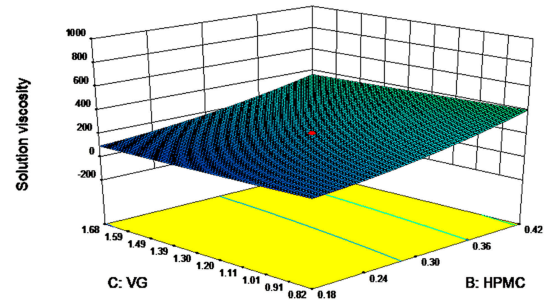

C

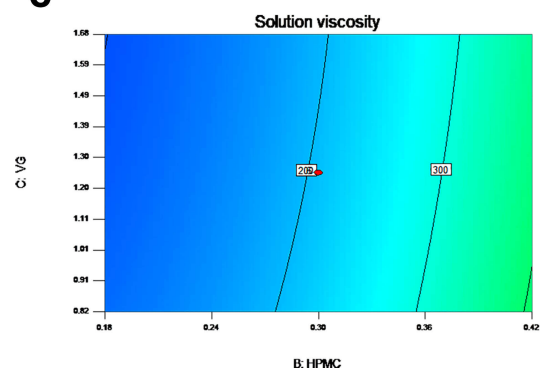

F

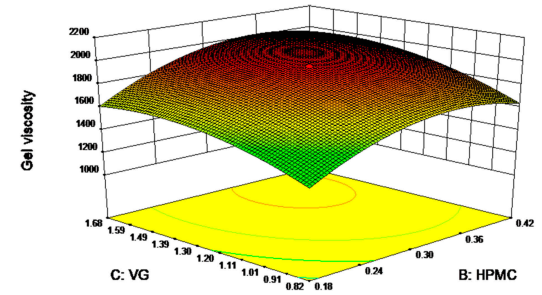

f

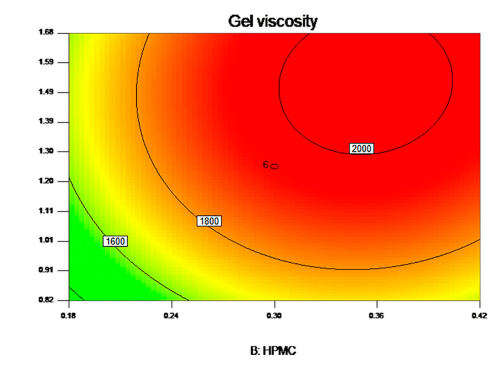

I vG: $1 \%$

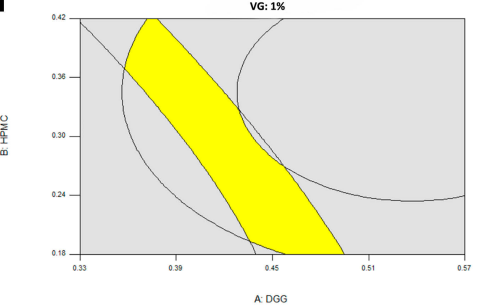

Figure 4 Three-dimensional surfaces and contour plots showing the influence of DGG, HPMC and VG. (A-C) 3D surface plots of DGG, HPMC and VG on solution viscosity; (a, b, c) contour plots of DGG, HPMC and VG on solution viscosity; (D-F) 3D surface plots of DGG, HPMC and VG on gel viscosity; (d, e, f) contour plots of DGG, HPMC and VG on gel viscosity; $(\mathbf{G}, \mathbf{H})$ target value ranges of solution viscosity and gel viscosity; (I) graphical optimization highlighting an area of operability. Abbreviations: DGG, deacetylated gellan gum; HPMC, hydroxypropyl methylcellulose; VG, glycerin.

of the human nasal cavity raised a requirement on the volume expansion coefficient of the gel, and the volume expansion coefficient of the gel after gelation should be less than $5 \%{ }^{45}$ The volume expansion coefficients of ISG and PAE-SLNs-ISG were $3.79 \% \pm 0.23 \%$ and $3.27 \% \pm$ $0.19 \%$, respectively. There are abundant capillaries and nerves in the nasal cavity of the human body. The thickness of the nasal mucosa is only $3 \mathrm{~mm}$, and it is in direct 
Table 4 Regression Equations of the Fitted Models

\begin{tabular}{|c|c|c|c|c|c|}
\hline Response $\mathbf{Y}$ & Model & Regression Equation & F-value & P-value & $\mathbf{R}^{2}$ \\
\hline $\begin{array}{l}\text { YI: solution } \\
\text { viscosity }\left(34^{\circ} \mathrm{C}\right)\end{array}$ & Quadratic & $\begin{array}{l}Y I=+207.00+273.87 \times A+138.09 \times B-16.66 \times C+103.71 \times A \times B-38.25 \times A \times C-3.62 \\
\times B \times C+100.84 \times A 2+39.95 \times B 2+3.41 \times C 2\end{array}$ & 97.87 & $<0.0001$ & 0.98 \\
\hline $\begin{array}{l}\text { Y2: gel viscosity } \\
\left(34^{\circ} \mathrm{C}\right)\end{array}$ & Quadratic & $\begin{array}{l}Y 2=+1955.00+318.76 \times A+155.95 \times B+143.09 \times C-1.47 \times A \times B+30.98 \times A \times C+ \\
17.48 \times B \times C-208.51 \times A 2-188.09 \times B 2-122.59 \times C 2\end{array}$ & 28.47 & $<0.0001$ & 0.96 \\
\hline
\end{tabular}

Table 5 Compositions of PAE-SLNs-ISG

\begin{tabular}{|l|l|}
\hline Ingredients & $\begin{array}{l}\text { Formulation Compositions } \\
(\%, w / v)\end{array}$ \\
\hline PAE-SLNs & 1.00 \\
DGG & 0.40 \\
HPMC & 0.30 \\
VG & 1.00 \\
Vitamin E & 0.01 \\
Chlorhexidine acetate & 0.01 \\
Distilled water & 100 \\
\hline
\end{tabular}

Abbreviations: PAE-SLNs-ISG, paeonol-solid lipid nanoparticles-in situ gel; PAESLNs, paeonol -solid lipid nanoparticles; DGG, deacetylated gellan gum; HPMC, hydroxypropyl methylcellulose; VG, glycerin.

contact with the external environment, resulting in the nasal mucosa more sensitive to external stimulus. The $\mathrm{pH}$ values of ISG and PAE-SLNs-ISG were $6.32 \pm 0.09$ and $6.43 \pm 0.15$, respectively, which were close to the normal physiological state of the human nasal cavity $(\mathrm{pH}$ $5.5 \sim 7.0$ ), and could effectively avoid the physiological stimulation of nasal mucosa. The in vitro mucoadhesion strengths of ISG and PAE-SLNs-ISG were $4127.29 \pm$ $59.21 \mathrm{dyne} / \mathrm{cm}^{2}$ and $4033 \pm 76.47 \mathrm{dyne} / \mathrm{cm}^{2}$, respectively, and there was no significant difference. Certain adhesion strength of the preparation can ensure a long contact and effectively increase the nasal absorption level of the drug and nanoparticles. ${ }^{46}$

\section{Rheology}

The in situ gel drug delivery system based on the nosebrain transport pathway mainly transports drugs directly to the brain through the olfactory nerve pathway, and the administration position is the olfactory mucosa. ${ }^{47}$ It is difficult for conventional nasal preparations to reach the deep olfactory area, which affects the brain targeting the delivery of drugs. With ideal rheological properties, the preparation could reach and stably stay in the olfactory region, and the nose-brain transport efficiency of the drug could be significantly improved. ${ }^{48}$ Figure 5 shows the rheological results of ISG and PAE-SLNs-ISG under different measurement modes.
Figure $5 \mathrm{~A}$ and $\mathrm{B}$ are the shear rate curves of ISG and PAE-SLNs-ISG, which describe the variations of viscosity (a) and shear stress (b) with shear rate, respectively. With the increase of shear rate, the viscosities of ISG solution and PAE-SLNs-ISG solution remained stable at a low level, and the viscosities of ISG gel and PAE-SLNs-ISG gel decreased. The shear stresses of ISG solution and PAESLNs-ISG solution increased slowly with the rise of shear rate. The shear stresses of ISG gel and PAE-SLNs-ISG gel increased first and then decreased with the increase of shear rate. The shear rate curves of ISG solution, ISG gel, PAE-SLNs-ISG solution and PAE-SLNs-ISG gel all had the same trend. The results of shear rate curves showed that ISG solution and PAE-SLNs-ISG solution were typical Newtonian fluids, and the low viscosity level was beneficial to ensure the flowability of the preparation. ISG gel and PAE-SLNs-ISG gel were pseudoplastic non-Newtonian fluids with rheological characteristics of shear thinning, which was beneficial to accelerate the erosion of gel and promote the drug release under the swinging of nasal cilia.

Figure 5C and D are the stress-strain curves of ISG and PAE-SLNs-ISG, which describe the variations of modulus (c) and shear strain (d) with shear stress, respectively. The loss modulus $\left(G^{\prime \prime}\right)$ and the storage modulus (G') could assess the viscosity and the elasticity of samples, respectively. ${ }^{49}$ In the low-stress range, both the G" and the G' of ISG gel and PAE-SLNs-ISG gel kept steady, which showed that the gels had a typical 3D network space structure. The storage modulus (G') of ISG gel and PAESLNs-ISG gel decreased sharply with the continuous increase of shear stress, indicating that the gel had a yield value. The shear strains of ISG solution, ISG gel, PAE-SLNs-ISG solution and PAE-SLNs-ISG gel all increased with the increase of shear stress.

Figure $5 \mathrm{E}$ and $\mathrm{F}$ are the frequency scanning curves of ISG and PAE-SLNs-ISG, which describe the variations of modulus (e) and loss coefficient (f) with scanning frequency, respectively. At a certain timescale and a specific 
A
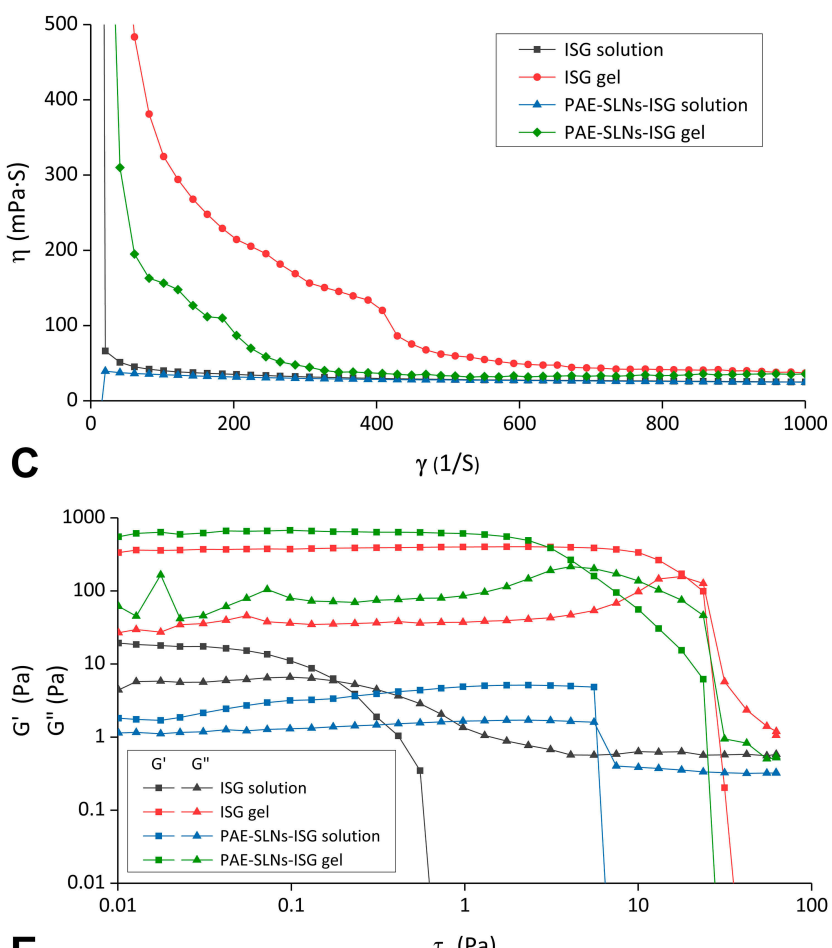

E

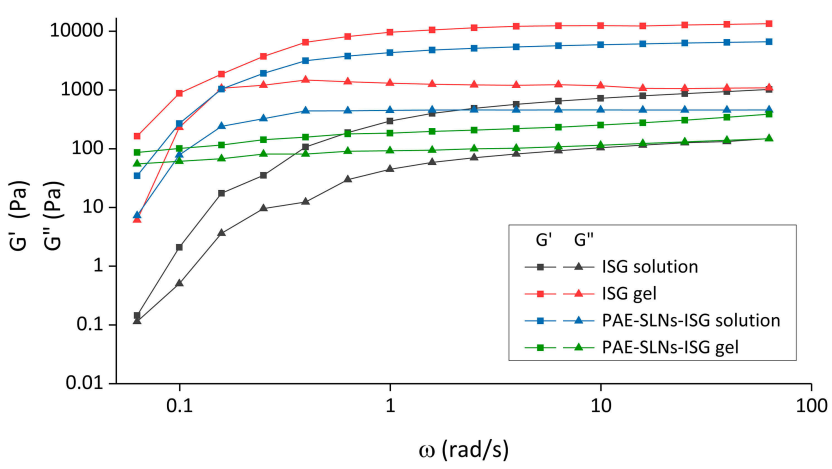

B
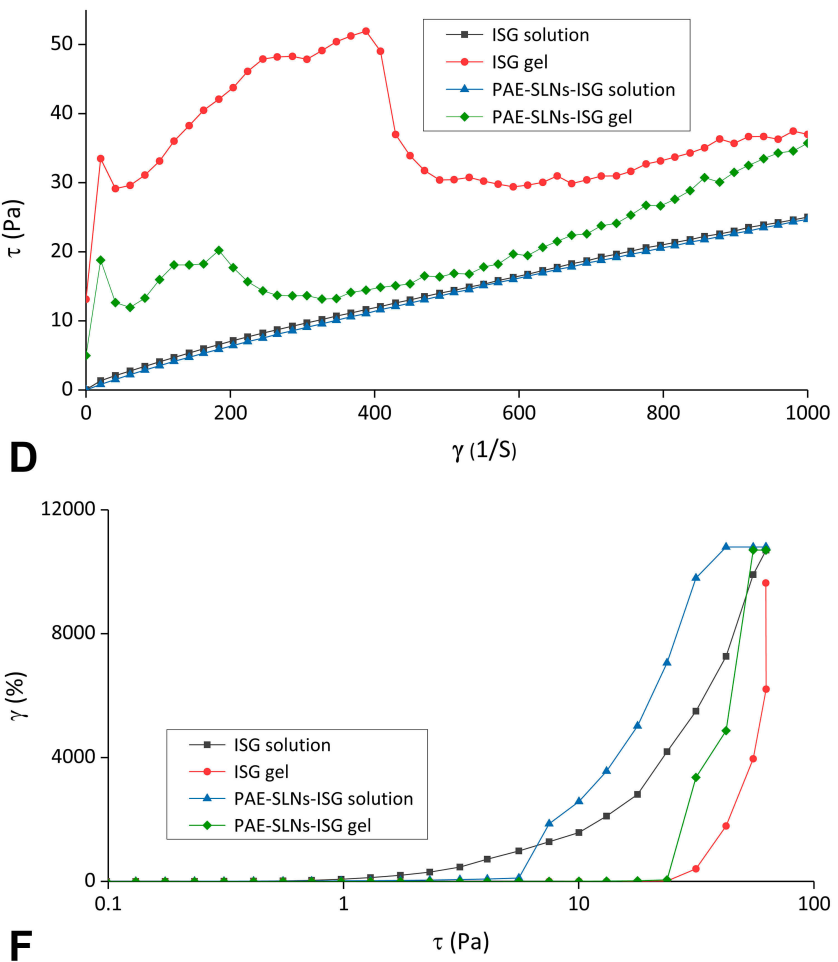

$\mathbf{F}$

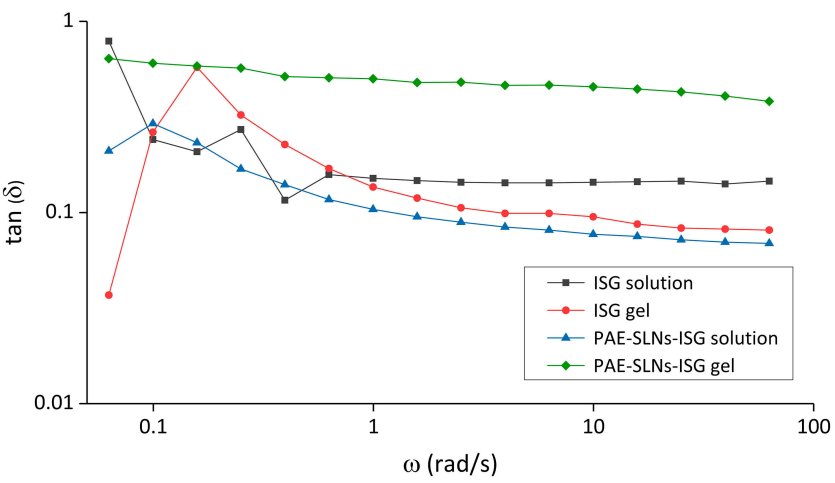

Figure 5 Rheological evaluations of ISG and PAE-SLNs-ISG at $34^{\circ} \mathrm{C}$. (A, B) The shear rate curves of ISG solution, ISG gel, PAE-SLNs-ISG solution and PAE-SLNs-ISG gel; (C, D) the stress-strain curves of ISG solution, ISG gel, PAE-SLNs-ISG solution and PAE-SLNs-ISG gel; (E, F) the frequency scanning curves of ISG solution, ISG gel, PAESLNs-ISG solution and PAE-SLNs-ISG gel.

Abbreviations: ISG, in situ gel; PAE-SLNs-ISG, paeonol-solid lipid nanoparticles-in situ gel; $\tau$, shear stress; $\eta$, viscosity; tan $\delta$, loss factor; $\gamma$, shear rate; G', storage modulus; G", loss modulus; $\omega$, frequency.

frequency, the relative relationship between loss modulus $\left(G^{\prime \prime}\right)$ and storage modulus $\left(G^{\prime}\right)$ determined the main properties of samples. At low scanning frequency, the G" and $\mathrm{G}^{\prime}$ of ISG gel and PAE-SLNs-ISG gel increased slowly and then maintained a stable level, indicating that the stability of the gel system was good. The loss coefficient $\tan \delta=\mathrm{G} / \mathrm{G}^{\prime}$. If the $\tan \delta$ became smaller, the elasticity of the preparation increased and the viscous behavior was less, and if it increased, the sample was easier to spread and the viscosity increased. ${ }^{50}$
The rheological results of ISG and PAE-SLNs-ISG indicated that the rheological behavior of ISG and PAESLNs-ISG was similar. The incorporation of PAE-SLNs into ISG had no significant effect on the rheological behavior of the gel. ISG and PAE-SLNs-ISG in the solution state were low viscosity Newtonian fluids. Good fluidity ensured accurate administration and smooth arrival of the preparation of the olfactory mucosa. In the gel state, ISG and PAE-SLNs-ISG were non-Newtonian pseudoplastic fluids with shear thinning, thixotropy and yield values. 


\section{In vitro Release}

The results of PAE released from PAE-SLNs and PAESLNs-ISG are shown in Figure 3E. At $1 \mathrm{~h}$, the cumulative release rates of PAE from PAE-SLNs and PAE-SLNs-ISG were $7.34 \% \pm 0.28 \%$ and $2.72 \% \pm 0.33 \%$, respectively. There was no burst drug release, which indirectly indicated that PAE was loaded in the core of PAE-SLNs. At $72 \mathrm{~h}$, the cumulative release rates of PAE from PAE-SLNs and PAESLNs-ISG were $84.04 \% \pm 2.71 \%$ and $64.89 \% \pm 3.14 \%$, respectively, and the drug release was relatively slow. The slow release of PAE could prolong the in vivo half-life and increase the bioavailability of the drug. The release of PAE from PAE-SLNs-ISG was divided into two consecutive processes: PAE-SLNs were first released from PAE-SLNsISG, and then PAE was released from PAE-SLNs. The gel formed by PAE-SLNs-ISG in response to cations had a 3D network structure, which offered a pathway for the release of PAE-SLNs from PAE-SLNs-ISG.

The five possible forms of drugs released from nanoparticles are as follows: desorption of drugs bound to the surface, diffusion through the nanoparticle matrix, diffusion through the wall of nano-capsules, nanoparticle matrix erosion and a combined erosion-diffusion process. Table 6 shows the kinetic mechanisms of PAE released from PAE-SLNs and PAE-SLNs-ISG. The release of PAE from PAE-SLNs conformed to the Higuchi model, and its release mechanism was diffusion. The release of PAE from PAE-SLNs-ISG was consistent with the KorsmeyerPeppas model, and the release behavior was a synergistic effect of skeleton erosion and drug diffusion. The main ways to realize erosion of PAE-SLNs-ISG gel skeleton in nasal environment were the swinging of nasal cilia and the erosion effect of nasal mucus on the gel.

\section{Cell Evaluation}

\section{In vitro Cytotoxicity}

Cytotoxicity evaluation is an important part of cellular compatibility evaluation, which can determine the acceptable therapeutic concentration. ${ }^{51}$ The cytotoxicity of

Table 6 Release Mechanisms of PAE

\begin{tabular}{|l|l|l|l|}
\hline Compound & Model & Regression Equation & $\mathbf{R}^{\mathbf{2}}$ \\
\hline PAE-SLNs & Higuchi & $\mathrm{Q}_{\mathrm{t}}=10.1994 \mathrm{t}^{1 / 2}-0.4066$ & 0.98 \\
PAE-SLNs- & Korsmeyer- & $\log \left(\mathrm{M}_{\mathrm{t}} / \mathrm{M}_{\infty}\right)=0.77463 \log (\mathrm{t})$ & 0.96 \\
ISG & Peppas & -1.66539 & \\
\hline
\end{tabular}

Abbreviations: PAE, paeonol; PAE-SLNs, paeonol-solid lipid nanoparticles; PAESLNs-ISG, paeonol-solid lipid nanoparticles-in situ gel. different SLNs to RPMI 2650 cells was studied based on the MTT method, and the results are shown in Figure 6A. The cell viabilities of bSLNs, PAE-SLNs, ISG and PAESLNs-ISG in the concentration range of $0.001 \mu \mathrm{g} / \mathrm{mL}$ to $10 \mu \mathrm{g} / \mathrm{mL}$ were higher than $90 \%$, indicating good cellular compatibility. The cell viabilities of bSLNs and PAESLNs were similar at different concentrations, and there was no significant difference, indicating that the loading of PAE did not affect the superior cellular compatibility of SLNs. In the preparation of SLNs, excessive surfactants were added to ensure that the particle size of SLNs was in nanometer size, but excessive free surfactants could increase cytotoxicity. ${ }^{52}$ The cell viabilities of bSLNs (No removal of free surfactants) and PAE-SLNs (No removal of free surfactants) decreased significantly with the increase of concentration, and the cell viabilities at 1000 $\mu \mathrm{g} / \mathrm{mL}$ were $24.20 \% \pm 2.44 \%$ and $25.90 \% \pm 0.35 \%$, respectively, showing strong cytotoxicity. The cell viabilities of bSLNs and bSLNs (No removal of free surfactants) were significantly different at different concentrations, indicating the necessity of continued dialysis for $3 \mathrm{~h}$ in $4^{\circ} \mathrm{C}$ water after the low-temperature curing of SLNs.

\section{Live/Dead Double Staining Method}

Calcein-AM is a cell staining reagent that can fluorescently label living cells. Calcein-AM can easily penetrate the membranes of living cells by enhancing the hydrophobicity based on Calcein. ${ }^{53}$ When it enters the cytoplasm, it will be hydrolyzed into Calcein by esterase and remain in the cell, emitting strong green fluorescence. ${ }^{54}$ Calcein-AM is the most suitable fluorescent probe to stain living cells because of its low cytotoxicity. The excitation and emission wavelengths of Calcein are $490 \mathrm{~nm}$ and $515 \mathrm{~nm}$, respectively. As a nuclear dye, Propidium Iodide (PI) cannot pass through the cell membrane of living cells. ${ }^{55}$ It passes through the disordered region of the dead cell membrane to reach the nucleus and is embedded in the DNA double helix of the cell to produce red fluorescence (excitation wavelength: $535 \mathrm{~nm}$, emission wavelength: 617 $\mathrm{nm})$, so PI only stains dead cells. ${ }^{56,57}$ Since both Calcein and PI-DNA can be stimulated at $490 \mathrm{~nm}$, both living and dead cells can be observed simultaneously by fluorescence microscopy. Only dead cells can be observed when stimulated at $545 \mathrm{~nm}$. The viabilities of RPMI 2650 cells after co-incubation with bSLNs, bSLNs (No removal of free surfactants), PAE-SLNs, PAE-SLNs (No removal of free surfactants), ISG and PAE-SLNs-ISG at $1000 \mu \mathrm{g} / \mathrm{mL}$ are shown in Figure 7. The red fluorescence intensity of dead 
A

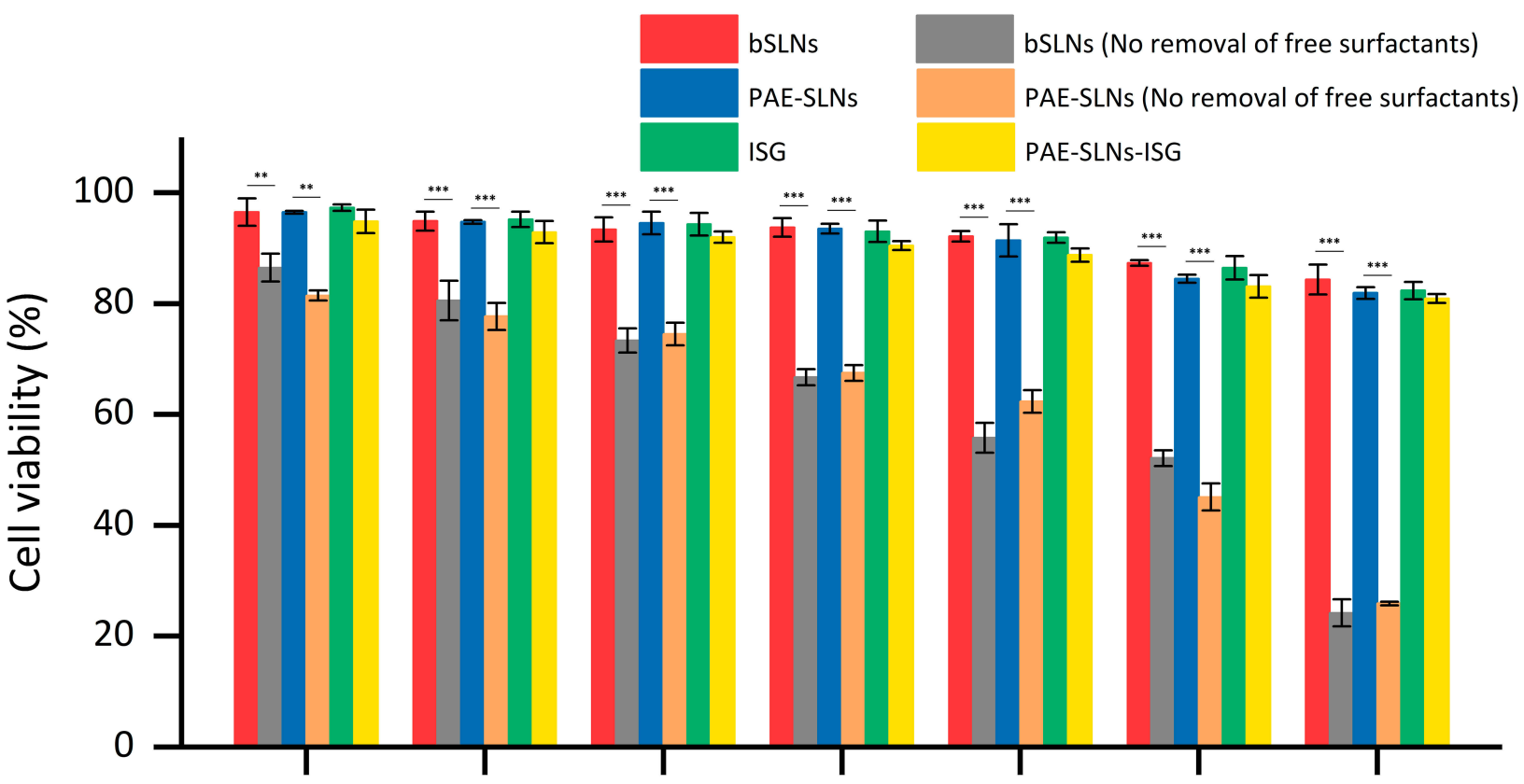

B

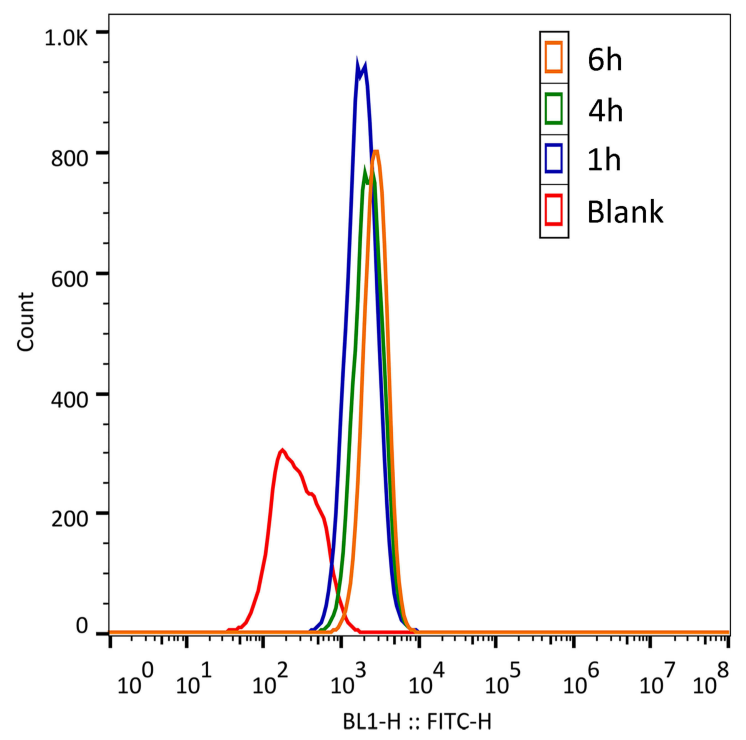

C

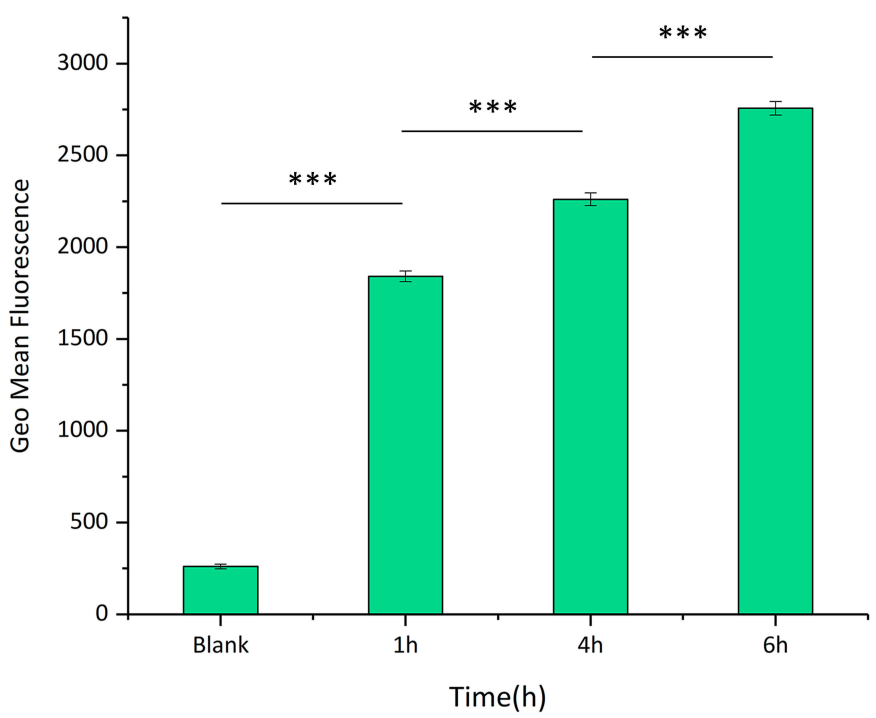

Figure 6 (A) Cell viabilities of RPMI 2650 cells following treatment with bSLNs $(0.001 \sim 1000 \mu \mathrm{g} / \mathrm{mL})$, bSLNs (No removal of free surfactants) $(0.00 \mathrm{I} \sim 1000 \mu \mathrm{gg} / \mathrm{mL})$, PAESLNs (0.00I $1000 \mu \mathrm{g} / \mathrm{mL})$, PAE-SLNs (No removal of free surfactants) $(0.00 \mathrm{I} \sim 1000 \mu \mathrm{g} / \mathrm{mL})$, ISG $(0.00 \mathrm{I} \sim 1000 \mu \mathrm{g} / \mathrm{mL})$ and PAE-SLNs-ISG $(0.00 \mathrm{I} \sim \mathrm{I} 000 \mu \mathrm{gg} / \mathrm{mL}) \mathrm{for}$ $24 \mathrm{~h}$. Data are expressed as mean $\pm S D, n=3$. (b) Fluorescence intensity values from RPMI 2650 cells (a total of 10,000 cells) suspensions were quantified by flow cytometry. Single parameter histogram (B) and geometric mean fluorescent intensity (C) of RPMI 2650 cells which treated with FITC-SLNs (I00 $\mu$ g/mL) for I h, $4 \mathrm{~h}$ and $6 \mathrm{~h}$, respectively. Data are expressed as mean $\pm \mathrm{SD}, \mathrm{n}=3$.

Notes: The differences between groups were performed using Student's $t$-test or one-way analysis of variance (ANOVA). $*^{*} p<0.00 \mathrm{I}$ and $* * * p<0.000 \mathrm{I}$ were considered statistically significant.

Abbreviations: PAE-SLNs, paeonol-solid lipid nanoparticles; PAE-SLNs-ISG, paeonol-solid lipid nanoparticles-in situ gel; bSLNs, blank solid lipid nanoparticles; ISG, in situ gel; RPMI, human nasal epithelial cells; FITC-SLNs, fluorescein isothiocyanate-solid lipid nanoparticles.

cells in bSLNs group, PAE-SLNs group, ISG group and PAE-SLNs-ISG group was similar to that in the blank group, indicating that the viability of cells was good. The red fluorescence intensity of dead cells in bSLNs group
(No removal of free surfactants) and PAE-SLNs group (No removal of free surfactants) was significantly higher than that in the blank group. The results of Live/Dead double staining method were consistent with those of the MTT 


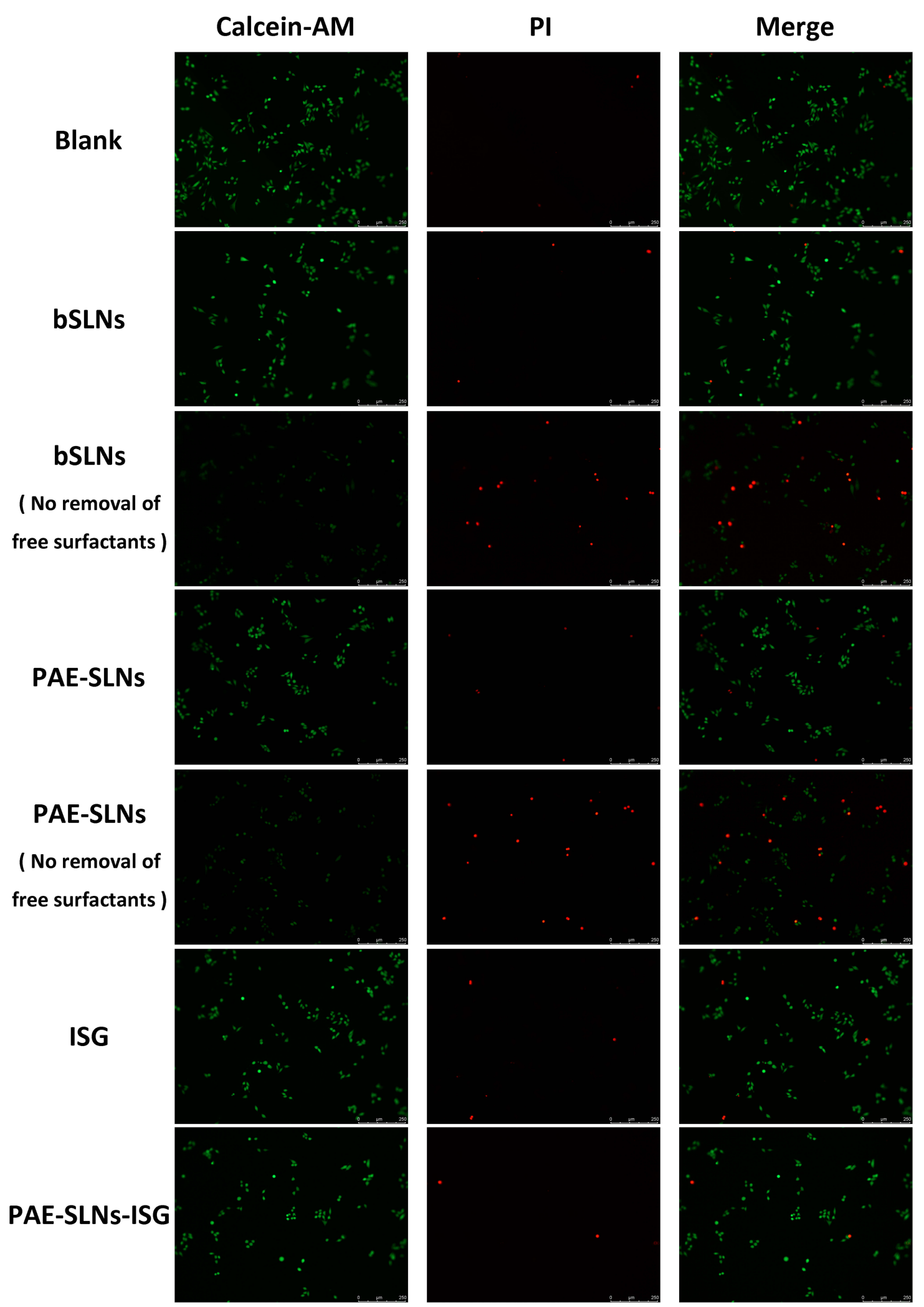

Figure 7 Calcein-AM/PI double staining method stained living cells and dead cells. Living cells were stained with Calcein-AM (green) and dead cells were stained with PI (red).

Abbreviations: PAE-SLNs, paeonol-solid lipid nanoparticles; PAE-SLNs-ISG, paeonol-solid lipid nanoparticles-in situ gel; bSLNs, blank solid lipid nanoparticles; ISG, in situ gel; Pl, propidium iodide. 
method, which indicated that bSLNs, PAE-SLNs, ISG and PAE-SLNs-ISG had acceptable cytotoxicity in a wide range of concentrations.

\section{Flow Cytometry}

Flow cytometry can be used for multi-parameter rapid quantitative analysis of cells in rapid linear movement. ${ }^{58}$

In this experiment, the uptake of solid lipid nanoparticles by RPMI 2650 cells was semi-quantitatively analyzed by flow cytometry, and the results are shown in Figure 6B and C.
The geometric mean fluorescent intensities of RPMI 2650 cells incubated with FITC-SLNs for $1 \mathrm{~h}, 4 \mathrm{~h}$ and $6 \mathrm{~h}$ were $1841 \pm 24,2261 \pm 27$ and $2757 \pm 22$, respectively, indicating that FITC-SLNs had good cellular compatibility and could be ingested efficiently by cells.

\section{In vivo Evaluation}

The biological distribution of nanoparticles is determined by a non-invasive in vivo imaging system of small animals. ${ }^{59}$ The low autofluorescence interference of athymic nude mice

A

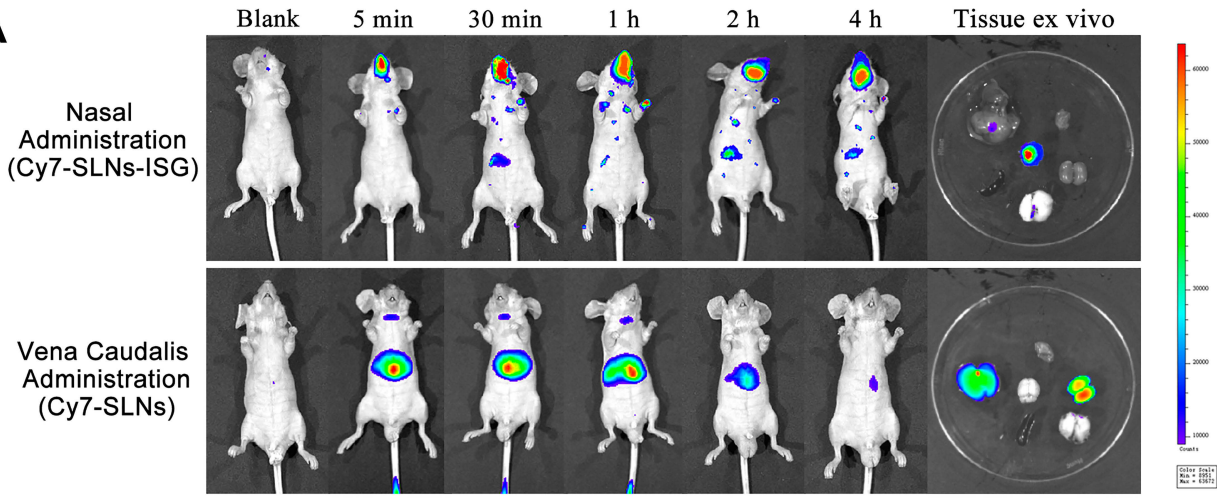

B
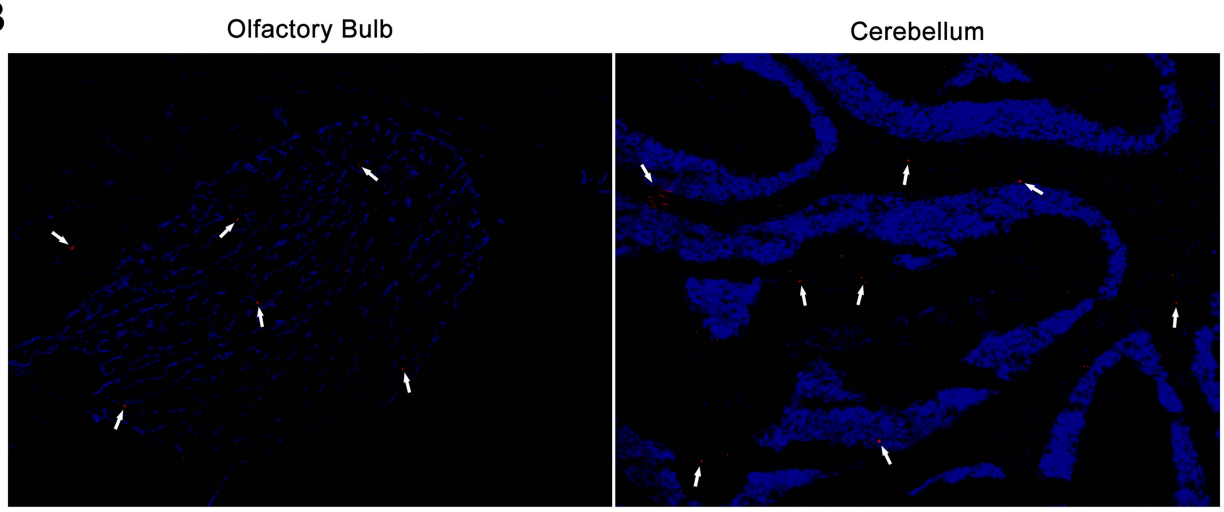

Striatum Substantia Nigra
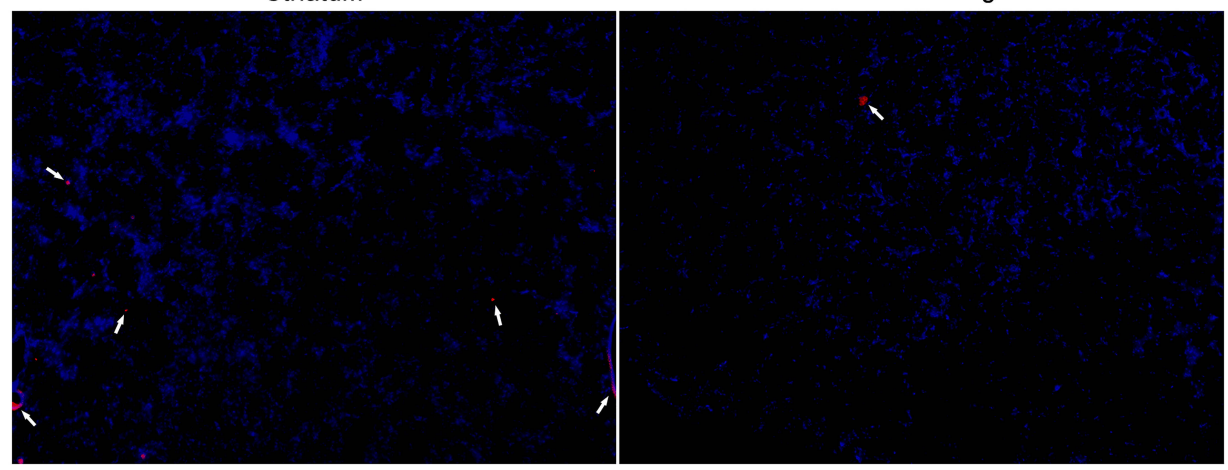

Figure 8 (A) Real-time biodistribution after administration of Cy7-SLNs-ISG in olfactory area and Cy7-SLNs via tail vein in nude mice. (B) Fluorescence response of different brain regions in SD rats after administration of Cy7-SLNs-ISG in olfactory area for $2 \mathrm{~h}$. Red fluorescence represents Cy7-SLNs, blue fluorescence represents DAPItreated nuclei.

Abbreviations: Cy7-SLNs, Cyanine7 NHS ester-solid lipid nanoparticles; Cy7-SLNs-ISG, Cyanine7 NHS ester-solid lipid nanoparticles-in situ gel; DAPI, 4',6-diamidino2-phenylindole; SD rats, Sprague-Dawley rats. 
makes it an ideal animal model for in vivo fluorescence imaging. ${ }^{60}$ Figure $8 \mathrm{~A}$ shows the difference of real-time biological distribution between the administration of SLNs by tail vein and the administration of SLNs-ISG in the olfactory area. After administration of Cy7-SLNs-ISG through the olfactory area, Cy7-SLNs showed fluorescence response in the brain region and showed a tendency of accumulation in the brain with the prolongation of transport time. Cy7-SLNs showed significant liver accumulation after tail vein administration, which was significantly reduced after $4 \mathrm{~h}$, and the metabolism was rapid. The fluorescence response results of in vitro tissues further verified the difference in the distribution of nanoparticles in vivo between the accumulation of brain area after administration of Cy7-SLNs-ISG in the olfactory area and the liver accumulation after administration of Cy7-SLNs via the tail vein.

At present, it is generally believed that the pathways of nose-brain transport are mainly neural pathway, mucosal pathway, blood circulation pathway and lymphoid pathway. ${ }^{61}$ The neural pathway is also known as the direct pathway. ${ }^{62}$ The neural pathway composed of olfactory nerve and trigeminal nerve can realize the direct braintargeted delivery of drugs, and the olfactory nerve pathway is the main pathway ${ }^{63}$ Figure $8 \mathrm{~B}$ shows the distribution of Cy7-SLNs in different brain regions after the administration of Cy7-SLNs-ISG in the olfactory region. The fluorescence response of Cy7-SLNs was clearly observed in the olfactory bulb, cerebellum and striatum, indicating that the effective nose-brain transport of Cy7-SLNs-ISG in the olfactory region was mainly through the "olfactory neuron-olfactory bulb-brain" pathway (olfactory nerve pathway).

Achieving the nose-brain transport of PAE can effectively avoid the first-pass effect of the liver and the inactivation of drug metabolism caused by complex blood environment, greatly reduce the drug accumulation in nontarget organs, directly bypass the transport limitation of the blood-brain barrier, and significantly improve the bioavailability of the brain region. The accurate quantitative transport efficiency of PAE-SLNs by PAE-SLNs-ISG nose-brain transport system and the cumulative difference of PAESLNs in specific brain regions will be studied in programmed experiments at an appropriate time.

\section{Conclusion}

The stability study of PAE in simulated biological samples indicated that the hepatic first-pass effect might be the cause of its low oral bioavailability. In this study, PAESLNs were successfully prepared by high-temperature emulsification-low-temperature curing combined with ultrasound, the nano-properties of PAE-SLNs met the requirements of nano-drugs. The PAE-SLNs-ISG drug delivery system was constructed by combining PAESLNs with ISG based on nose-brain transport pathway. PAE-SLNs-ISG solution could rapidly respond to cations in nasal mucus to form a non-Newtonian pseudo-plastic gel, the characterization of PAE-SLNs-ISG was consistent with the preparation requirements of nasal olfactory administration. PAE-SLNs had a low level of cytotoxicity, FITC-SLNs could be efficiently absorbed, and solid lipid nanoparticles had good cellular compatibility. PAE-SLNsISG nose-brain transport system can effectively transport SLNs to the brain region along the "olfactory neuronolfactory bulb-brain" pathway (olfactory nerve pathway).

\section{Acknowledgments}

The authors would like to thank Jinan Changge Biotechnology Co., Ltd., for providing materials and reagents. They would also like to thank Shiyanjia Lab for the support of testing.

\section{Disclosure}

The authors report no conflicts of interest in this work.

\section{References}

1. He L, Tong X, Zeng J, et al. Paeonol suppresses neuroinflammatory responses in lps-activated microglia cells. Inflammation. 2016;39 (6):1904-1917. doi:10.1007/s10753-016-0426-Z

2. Shi X, Chen Y, Liu H, et al. Therapeutic effects of paeonol on methyl-4-phenyl -1, 2, 3, 6-tetrahydropyridine/probenecid-induced Parkinson's disease in mice. Mol Med Rep. 2016;14:2397-2404.

3. Zhao Y, Fu B, Zhang X, et al. Paeonol pretreatment attenuates cerebral ischemic injury via upregulating expression of pAkt, Nrf2, HO-1 and ameliorating BBB permeability in mice. Brain Res Bull. 2014;109:61-67.

4. Gyawal A, Krol S, kang YS. Involvement of a novel organic cation transporter in paeonol transport across the blood-brain barrier. Biomol Ther. 2019;27:290-301.

5. Zsikó S, Cutcher K, Kovács A, et al. Nanostructured lipid carrier gel for the dermal application of lidocaine: comparison of skin penetration testing methods. Pharmaceutics. 2019;11:310.

6. Tapeinos C, Battaglini M, Ciofani G. Advances in the design of solid lipid nanoparticles and nanostructured lipid carriers for targeting brain diseases. J Controlled Release. 2017;264:306-332.

7. Tzeyung AS, Shadab M, Bhattamisra SK, et al. Fabrication, optimization, and evaluation of rotigotine-loaded chitosan nanoparticles for nose-to-brain delivery. Pharmaceutics. 2019;11:26.

8. Espinoza LC, Abreu MS, Clares B, et al. Formulation strategies to improve nose-to-brain delivery of donepezil. Pharmaceutics. 2019;11:64.

9. Bonferoni MC, Rossi S, Sandri G, et al. Nanoemulsions for "nose-tobrain" drug delivery. Pharmaceutics. 2019;11:84.

10. Bonferoni MC, Ferraro L, Pavan B, et al. Uptake in the central nervous system of geraniol oil encapsulated in chitosan oleate following nasal and oral administration. Pharmaceutics. 2019;11 (3):106. doi:10.3390/pharmaceutics11030106 
11. Chu K, Chen L, Xu W, et al. Preparation of a paeonol-containing temperature-sensitive in situ gel and its preliminary efficacy on allergic rhinitis. Int J Mol Sci. 2013;14:6499-6515.

12. Youssef N, Kassem AA, Farid RM, et al. A novel nasal almotriptan loaded solid lipid nanoparticles in mucoadhesive in situ gel formulation for brain targeting: preparation, characterization and in vivo evaluation. Int J Pharm. 2018;548:609-624.

13. Mura P, Mennini N, Nativi C, et al. In situ mucoadhesive-thermosensitive liposomal gel as a novel vehicle for nasal extended delivery of opiorphin. Eur J Pharm Biopharm. 2018;122:54-61.

14. Ahmed TA, Khalid ME-S, Osama AAA, et al. Superiority of TPGS loaded micelles in the brain delivery of vinpocetine via administration of thermosensitive intranasal gel. Int J Nanomed. 2019;14:5555-5567.

15. Dewan M, Sarkar G, Bhowmik M, et al. Effect of gellan gum on the thermogelation property and drug release profile of poloxamer 407 based ophthalmic formulation. Int J Biol Macromol. 2017;102:258-265.

16. Zaki NM, Awad GA, Mortada ND, et al. Enhanced bioavailability of metoclopramide $\mathrm{HCl}$ by intranasal administration of a mucoadhesive in situ gel with modulated rheological and mucociliary transport properties. Eur J Pharm Sc. 2007;32:296-307.

17. Hao JF, Zhao J, Zhang S, et al. Fabrication of an ionic-sensitive in situ gel loaded with resveratrol nanosuspensions intended for direct nose-to-brain delivery. Colloids Surf B. 2016;147:376-386.

18. Salunke SR, Patil SB. Ion activated in situ gel of gellan gum containing salbutamol sulphate for nasal administration. Int $J$ Biol Macromol. 2016;87:41-47.

19. Fatouh AM, Elshafeey AH, Abdelbary A. Agomelatine-based in situ gels for brain targeting via the nasal route: statistical optimization, in vitro, and in vivo evaluation. Drug Deliv. 2017;24:1077-1085

20. Mahajan HS, Tyagi V, Lohiya G, et al. Thermally reversible xyloglucan gels as vehicles for nasal drug delivery. Drug Deliv. 2012;19:270-275.

21. Hosny KM, Hassan AH. Intranasal in situ gel loaded with saquinavir mesylate nanosized microemulsion: preparation, characterization, and in vivo evaluation. Int J Pharm. 2014;475:191-197.

22. Shah V, Sharma M, Pandya R, et al. Quality by design approach for an in situ gelling microemulsion of lorazepam via intranasal route. mater. Sci Eng Carbon. 2017;75:1231-1241.

23. Mahajan HS, Gattani S. In situ gels of metoclopramide hydrochloride for intranasal delivery: in vitro evaluation and in vivo pharmacokinetic study in rabbits. Drug Deliv. 2010;17:19-27.

24. Gao Y, Liu R, Gautam N, et al. Determination of the in vitro metabolic stability and metabolites of the anticancer derivative riccardin D-N in human and mouse hepatic S9 fractions using HPLC-Q-LITMS. J Pharm Biomed Anal. 2019;174:734-743.

25. Baea M, Leea Y, Parka YK, et al. Astaxanthin attenuates the increase in mitochondrial respiration during the activation of hepatic stellate cells. J Nutr Biochem. 2019;71:82-89.

26. Kwon MH, Jeong JS, Ryu J, et al. Pharmacokinetics and brain distribution of the active components of da-9805, saikosaponin a, paeonol, and imperatorin in rats. Pharmaceutics. 2018;10:133.

27. Cho PJ, Paudel S, Lee D, et al. Characterization of CYPs and UGTs involved in human liver microsomal metabolism of osthenol. Pharmaceutics. 2018;10:141.

28. Khames A, Khalee MA, Mohamed FE-B, et al. Natamycin solid lipid nanoparticles - sustained ocular delivery system of higher corneal penetration against deep fungal keratitis: preparation and optimization. Int J Nanomed. 2019;14:2515-2531.

29. Kang J-H, Chon J, Kim Y-I, et al. Preparation and evaluation of tacrolimus-loaded thermosensitive solid lipid nanoparticles for improved dermal distribution. Int $J$ Nanomed. 2019;14: 5381-5396.

30. Evan M CEM, Quijano AR, Seo YE, et al. Biodegradable PEG-poly (u-pentadecalactone-co-p-dioxanone) nanoparticles for enhanced and sustained drug delivery to treat brain tumors. Biomaterials. 2018;178:193-203.
31. Stella B, Peira E, Dianzani C, et al. Development and characterization of solid lipid nanoparticles loaded with a highly active doxorubicin derivative. Nanomaterials. 2018;8:110.

32. Chirio D, Peira E, Dianzani C, et al. Development of solid lipid nanoparticles by cold dilution of microemulsions: curcumin loading, preliminary in vitro studies, and biodistribution. Nanomaterials. 2019;9:230.

33. Cao SL, Zhang QZ, Jiang XG. Preparation of ion-activated in situ gel systems of scopolamine hydrobromide and evaluation of its antimotion sickness efficacy. Acta Pharmacol Sin. 2007;28:584-590.

34. Gabal YM, Kamel AO, Sammour OA, et al. Sammour an effect of surface charge on the brain delivery of nanostructured lipid carriers in situ gels via the nasal route. Int J Pharm. 2014;473:442-457.

35. Gänger S, Schindowski K. Tailoring formulations for intranasal nose-to-brain delivery: a review on architecture, physicochemical characteristics and mucociliary clearance of the nasal olfactory mucosa. Pharmaceutics. 2018;10:116.

36. Ozbilgın ND, Saka OM, Bozkır A. Preparation and in vitro/in vivo evaluation of mucosal adjuvant in situ forming gels with diphtheria toxoid. Drug Deliv. 2014;21:140-147.

37. Qian S, Wong YC, Zuo Z. Development, characterization and application of in situ gel systems for intranasal delivery of tacrine. Int J Pharm. 2014;468:272-282.

38. Ghadiri M, Young PM, Traini D. Strategies to enhance drug absorption via nasal and pulmonary routes. Pharmaceutics. 2019;11:113.

39. Chen Y-S, Chiu Y-H, Yuan-Sheng L, et al. Integration of PEG 400 into a self-nano emulsifying drug delivery system improves drug loading capacity and nasal mucosa permeability and prolongs the survival of rats with malignant brain tumors. Int $J$ Nanomed. 2019;14:3601-3613.

40. Cao SL, Ren XW, Zhang QZ, et al. In situ gel based on gellan gum as new carrier for nasal administration of mometasone furoate. Int J Pharm. 2009;365:109-115.

41. Musumeci T, Bonaccorso A, Puglisi G. Epilepsy disease and nose-tobrain delivery of polymeric nanoparticles: an overview. Pharmaceutics. 2019;11:118

42. Sonvico F, Clementino A, Buttini F, et al. Surface-modified nanocarriers for nose-to-brain delivery: from bioadhesion to targeting. Pharmaceutics. 2018;10:34.

43. Ahmed S, Gull A, Aqil M, et al. Poloxamer-407 thickened lipid colloidal system of agomelatine for brain targeting: characterization, brain pharmacokinetic study and behavioral study on wistar rats. Colloids Surf B. 2019;181:426-436.

44. Zaafarany GME, Soliman ME, Mansour S, et al. A tailored thermosensitive PLGA-PEG-PLGA/emulsomes composite for enhanced oxcarbazepine brain delivery via the nasal route. Pharmaceutics. 2018;10:217.

45. Salem HF, Kharshoum RM, Abou-Taleb HA, et al. Nanosized transferosome-based intranasal in situ gel for brain targeting of resveratrol: formulation, optimization, in vitro evaluation, and in vivo pharmacokinetic study. AAPS PharmSciTech. 2019;20:181.

46. NižićL, Ugrina I, Špoljarić D, et al. Innovative sprayable in situ gelling fluticasone suspension: development and optimization of nasal deposition. Int J Pharm. 2019;04:015.

47. Zhou H, Ichikawa A, Takahashi YI, et al. Nanogels of succinylated glycol chitosan -succinyl prednisolone conjugate: preparation, in vitro characteristics and therapeutic potential. Pharmaceutics. 2019;11:333.

48. Gholizadeh H, Cheng S, Pozzoli M, et al. Smart thermosensitive chitosan hydrogel for nasal delivery of ibuprofen to treat neurological disorders. Exp Opin Drug Del. 2019;1742:5247.

49. Xie H, Li L, Sun Y, et al. An available strategy for nasal brain transport of nanocomposite based on pamam dendrimers via in situ gel. Nanomaterials. 2019;9:147.

50. Tatke A, Dudhipala N, Janga KY, et al. In situ gel of triamcinolone acetonide-loaded solid lipid nanoparticles for improved topical ocular delivery: tear kinetics and ocular disposition studies. Nanomaterials. 2019;9:33. 
51. Silva AM, Alvarado HL, Abrego G, et al. In vitro cytotoxicity of oleanolic/ursolic acids-loaded in plga nanoparticles in different cell lines. Pharmaceutics. 2019;11:362.

52. Sandri G, Motta S, Bonferoni MC, et al. Chitosan-coupled solid lipid nanoparticles: tuning nanostructure and mucoadhesion. Eur J Pharm Biopharm. 2016;110:13-18.

53. Jannina V, Blasb L, Chevriera S, et al. Evaluation of the digestibility of solid lipid nanoparticles of glyceryl dibehenate produced by two techniques: ultrasonication and spray-flash evaporation. Eur J Pharm Biopharm. 2018;111:91-95.

54. Kim CH, Sung SW, Lee ES, et al. Sterically stabilized RIPL peptide-conjugated nanostructured lipid carriers: characterization, cellular uptake, cytotoxicity, and biodistribution. Pharmaceutics. 2018;10:199.

55. Montenegro L, Panico AM, Santagati LM, et al. Solid lipid nanoparticles loading idebenone ester with pyroglutamic acid: in vitro antioxidant activity and in vivo topical efficacy. Nanomaterials. 2019;9:43.

56. Arana L, Cordero LB, Sarasola LI, et al. Solid lipid nanoparticles surface modification modulates cell internalization and improves chemotoxic treatment in an oral carcinoma cell line. Nanomaterials. 2019;9:464.

57. Mishra V, Bansal KK, Verma A, et al. Solid lipid nanoparticles: emerging colloidal nano drug delivery systems. Pharmaceutics. 2018;10:191.
58. Baek JS, Na YG, Cho CW. Sustained cytotoxicity of wogonin on breast cancer cells by encapsulation in solid lipid nanoparticles. Nanomaterials. 2018;8:159.

59. Wu X, Chen $\mathrm{H}$, Wu $\mathrm{C}$, et al. Inhibition of intrinsic coagulation improves safety and tumor-targeted drug delivery of cationic solid lipid nanoparticles. Biomaterials. 2018;156:77-87.

60. Shen MY, Liu TI, Yu TW, et al. Hierarchically targetable polysaccharide-coated solid lipid nanoparticles as an oral chemo/ thermotherapy delivery system for local treatment of colon cancer. Biomaterials. 2019;197:86-100.

61. Meng Q, Wang A, Hua H, et al. Intranasal delivery of Huperzine A to the brain using lactoferrin-conjugated $\mathrm{N}$-trimethylated chitosan surface-modified PLGA nanoparticles for treatment of Alzheimer's disease. Int J Nanomed. 2018;13:705-718.

62. Yan X, Lixiao X, Chenchen B, et al. Lactoferrin-modified rotigotine nanoparticles for enhanced nose-to-brain delivery: LESA-MS/ MSbased drug biodistribution, pharmacodynamics, and neuroprotective effects. Int J Nanomed. 2018;13:273-281.

63. Perez AP, Mundiña-Weilenmann C, Romero EL, et al. Increased brain radioactivity by intranasal 32P-labeled siRNA dendriplexes within in situ-forming mucoadhesive gels. Int $J$ Nanomed. 2012;7:1373-1385.
International Journal of Nanomedicine

\section{Publish your work in this journal}

The International Journal of Nanomedicine is an international, peerreviewed journal focusing on the application of nanotechnology in diagnostics, therapeutics, and drug delivery systems throughout the biomedical field. This journal is indexed on PubMed Central, MedLine, CAS, SciSearch ${ }^{\circledR}$, Current Contents ${ }^{\mathbb{B}} /$ Clinical Medicine,

\section{Dovepress}

Journal Citation Reports/Science Edition, EMBase, Scopus and the Elsevier Bibliographic databases. The manuscript management system is completely online and includes a very quick and fair peer-review system, which is all easy to use. Visit http://www.dovepress.com/ testimonials.php to read real quotes from published authors. 